\title{
Modeling and Simulation of the Degradation of Perfluorinated Ion-Exchange Membranes in PEM Fuel Cells
}

\author{
A. A. Shah, ${ }^{\mathrm{a}, \mathrm{z}}$ T. R. Ralph, ${ }^{\mathrm{b}, *}$ and F. C. Walsh ${ }^{\mathrm{a}, *}$ \\ ${ }^{a}$ Electrochemical Engineering Laboratory, Energy Technology Research Group, School of Engineering \\ Sciences, University of Southampton, Highfields, Southampton SO17 1BJ, United Kingdom \\ ${ }^{b}$ Johnson Matthey Fuel Cells, Lydiard Fields, Great Western Way, Swindon SN5 8AT, United Kingdom
}

\begin{abstract}
A polymer electrolyte membrane (PEM) fuel cell model that incorporates chemical degradation in perfluorinated sulfonic acid membranes is developed. The model is based on conservation principles and includes a detailed description of the transport phenomena. A degradation submodel describes the formation of hydrogen peroxide via distinct mechanisms in the cathode and anode, together with the subsequent formation of radicals via Fenton reactions involving metal-ion impurities. The radicals participate in the decomposition of reactive end groups to form carboxylic acid, hydrogen fluoride, and $\mathrm{CO}_{2}$. Degradation proceeds through unzipping of the polymer backbone and cleavage of the side chains. Simulations are presented, and the numerical code is shown to be extremely time-efficient. Known trends with respect to operating conditions are qualitatively captured, and the exhibited behavior is shown to be robust to changes in the rate constants. The feasibility of a chemical degradation mechanism based on peroxide and radical formation is discussed.

(C) 2009 The Electrochemical Society. [DOI: 10.1149/1.3077573] All rights reserved.
\end{abstract}

Manuscript submitted October 27, 2008; revised manuscript received January 8, 2009. Published February $12,2009$.

The proton exchange membrane (PEM) fuel cell has long been recognized as an important component of the future hydrogen economy. Although significant progress has been made on issues related to performance, the commercial viability of the PEM fuel cell is largely dependent upon overcoming a host of durability and degradation issues ${ }^{1}$ these include poisoning of the anode by carbon monoxide and hydrogen sulfide, ${ }^{2-6}$ platinum sintering and dissolution, ${ }^{7,8}$ degradation of carbon supports, ${ }^{9,10}$ and membrane failure. ${ }^{11,12}$ Indeed, the lifetime of the PEM fuel cell is highly dependent on the lifetime of the ion-exchange membrane. The majority of membranes used in PEM fuel cells have a perfluorinated backbone and are modified to include sulfonic groups that facilitate the transport of protons. Typical examples of such materials are Aciplex, Flemion, Dow, and DuPont's Nafion, shown in Fig. 1.

There are several known failure modes for these perfluorosulfonic acid (PFSA) membranes during fuel cell operation, involving mechanical, thermal, and electrochemical processes. Mechanical failure can occur in many forms, including tears, cracks, punctures, pinholes, and inadequate sealing, which can lead to reactant crossover and unwanted reactions. Among the causes of mechanical failure are manufacturing imperfections, ${ }^{13}$ inadequate humidification and high temperatures, ${ }^{14-17}$ excessive swelling, ${ }^{18}$ membrane stiffening related to physical cross-linking induced by platinum cations, ${ }^{19}$ and localized heating caused by $\mathrm{O}_{2}$ evolution. ${ }^{20}$ Collier et al. have provided a detailed review of these and other causes. ${ }^{11}$

The most cited cause of membrane failure is chemical degradation, although in reality failure is likely to be a combination of both mechanical and chemical phenomena, the interplay between which is not fully understood. The two paramount steps in the sequence that leads to chemical degradation are $(i)$ formation of the attacking species and (ii) attack by the species on the membrane structure. Both remain the subject of much debate. There is, however, a consensus that the chemical degradation of PFSA membranes is initiated by free radical attack on reactive end groups. ${ }^{11,12}$ Carboxylic acid (or other H-containing) end groups can form during polymerization or as a result of chemical reaction and are highly vulnerable to attack. ${ }^{21,22}$ Curtin et al. proposed a degradation mechanism in which a carboxylic acid group $(\mathrm{COOH})$ attached to a $\mathrm{CF}_{2}$ group reacts with hydroxyl radicals $(\cdot \mathrm{OH})$ to release $\mathrm{CO}_{2}$ and $\mathrm{HF}$. Another $\mathrm{COOH}$ group is formed on the polymer main chain, attached to the $\mathrm{CF}_{2}$ group adjacent to the original $\mathrm{COOH}$ group, and the process is repeated, "unzipping" the polymer backbone. This and other pos-

* Electrochemical Society Active Member

z E-mail: A.Shah@soton.ac.uk sible mechanisms are discussed further in the Membrane Attack Mechanisms section.

The most likely source of the radicals is decomposition of $\mathrm{H}_{2} \mathrm{O}_{2}$ on metal impurities that are present in the membrane. The concentration of such impurities can increase during operation due to leaching from the membrane electrode assembly (MEA) and other system components. ${ }^{11,16,23,24}$ The $\mathrm{H}_{2} \mathrm{O}_{2}$ can form on both the anode and cathode, in the former case through $\mathrm{O}_{2}$ crossover and in the latter case as a result of the two-electron $\mathrm{O}_{2}$ reduction. ${ }^{23,25,26}$ Details are provided in the Hydrogen Peroxide Formation and Radical Formation sections.

The time scale associated with membrane degradation severely limits experimental studies. A number of techniques have been employed to "simulate" real-time degradation, including the ex situ Fenton's test, ${ }^{15,23,27,28}$ accelerated tests at open-circuit voltage, ${ }^{29}$ and potential or relative-humidity (RH) cycling. ${ }^{29,30}$ The problem is further compounded by the challenges posed in measuring the small concentrations of species that can provide direct evidence of failure or in visualizing the degradation itself. Recent reviews of membrane degradation have highlighted these issues. ${ }^{11,12}$

Modeling and simulation are well-established tools for PEM fuel cell study and have proven to be useful in the analysis of performance-related issues. ${ }^{31,32}$ In contrast, there are few models of degradation, particularly of the ion-exchange membrane. This is somewhat surprising considering its relevance to the commercial viability of PEM fuel cells and the aforementioned challenges associated with laboratory experiment. Xie and Hayden ${ }^{27}$ derived a model for the degradation of PFSA membranes based on the unzipping mechanism and scission of the backbone at side-chain loca-

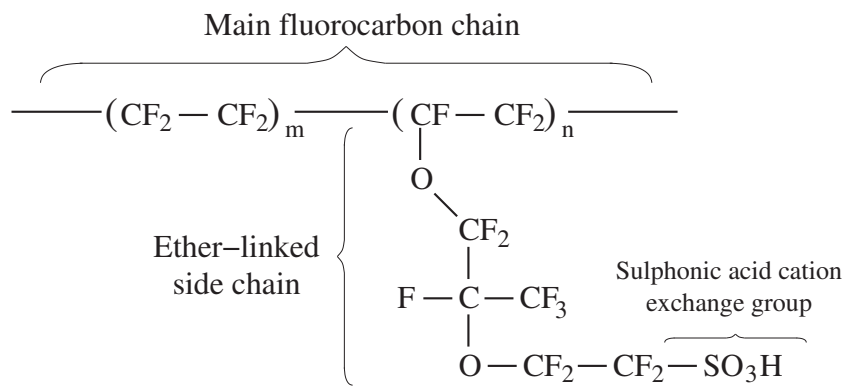

Figure 1. Structure of Nafion, which has an aliphatic perfluorinated backbone and ether-linked side chains ending in sulfonate cation exchange sites. ${ }^{94}$ The equivalent weight satisfies $E W=100 m+446$, assuming that $n=1$. For $E W=1100, m \approx 6.5$. 
tions, leaving the $\mathrm{COOH}$ group attached to the remaining fragments. After several approximations are made, the resulting equations are solved explicitly, yielding expressions for normalized carboxylic acid and fluorine concentrations. Their model does not include a description of peroxide and radical formation, the effects of operating conditions, and transport phenomena in the MEA components. It is, therefore, of limited applicability to the degradation of membranes in fuel cells.

Below, a detailed model of chemical degradation is developed, motivated largely by the difficulties associated with experimental characterization. The evolution of $\mathrm{H}_{2} \mathrm{O}_{2}, \cdot \mathrm{OH}$, and $\cdot \mathrm{OOH}$ radicals, $\mathrm{HF}$, carboxylic acid, and $\mathrm{CF}_{2}$ groups are included in the model. Two degradation routes are considered, namely, an unzipping mechanism and side-chain cleavage resulting in the formation of perfluoro(3oxa-5-methyl)pentane-1-sulfonic-5-carboxylic diacid groups, which are regularly detected in effluent water collected during degradation experiments. ${ }^{12,15,27,33}$ In modeling membrane, as well as other forms of degradation, it is important to take into account the transport phenomena in the cell, the properties of the cell components, and the conditions under which the fuel cell is operated; the rate of reactant crossover, the membrane thickness, the operating temperature, the relative humidity, and the cell voltage are known to exert a strong influence on the extent of degradation. ${ }^{15-17,23,34-39}$ They are incorporated into the model explicitly.

Numerical simulations based on the model are performed in a hierarchical manner, beginning with the simplest case of an unlimited supply of metal-ion impurities and no side-chain cleavage. The numerical simulations yield predictions of the rates of $\mathrm{H}_{2} \mathrm{O}_{2}, \cdot \mathrm{OH}$, and $\mathrm{COOH}$ formation, unzipping of the backbone, side-chain cleavage, and HF generation. The evolutions of these quantities with respect to time and variations in the operating conditions are discussed. The observed trends are compared to experimental results, ${ }^{11,12}$ and the feasibility of a model of chemical membrane degradation based on peroxide and radical formation is assessed. In order to affirm the basic phenomenology, parametric studies in several unknown reaction constants are conducted.

\section{Membrane Degradation}

Membrane degradation is a complex process that is poorly understood. The model developed in this paper considers chemical forms of degradation, for which there is strong evidence (from both Fenton and accelerated life tests) to suggest that peroxide formation is a precursor, leading to intermediate radical formation and eventual attack of the membrane structure. Although this mechanism is widely accepted, not all aspects are universally acknowledged. Questions regarding the applicability of the results from simulated degradation experiments to practical fuel cells, the location of peroxide formation, the location of attack, the attacking species, and additional modes of degradation remain unanswered at the present time. These issues are briefly discussed below. The reader is referred to recent reviews by Collier et al. and Schiraldi for further details. $^{11,12}$

Hydrogen peroxide formation.-Formation of peroxide and radicals in PEM fuel cells is considered to be a key step in membrane degradation. There is still debate over which electrode experiences the highest quantities of these species and by what mechanisms they are formed. Preferential degradation of the membrane has been observed at both the anode and cathode, depending on the operating conditions; ${ }^{11}$ if peroxide ions lead to radical formation, this would suggest separate mechanisms in the anode and cathode and dominance of one over the other depending on the fuel cell conditions and, probably, the component properties. Several factors may contribute to preferential degradation, including water transport, catalyst corrosion in the cathode, catalyst migration, and preferential end-plate corrosion. ${ }^{19,25,37}$

To fully describe the problem of selecting the correct mechanisms, the electrode reactions, oxygen reduction reaction (ORR) and

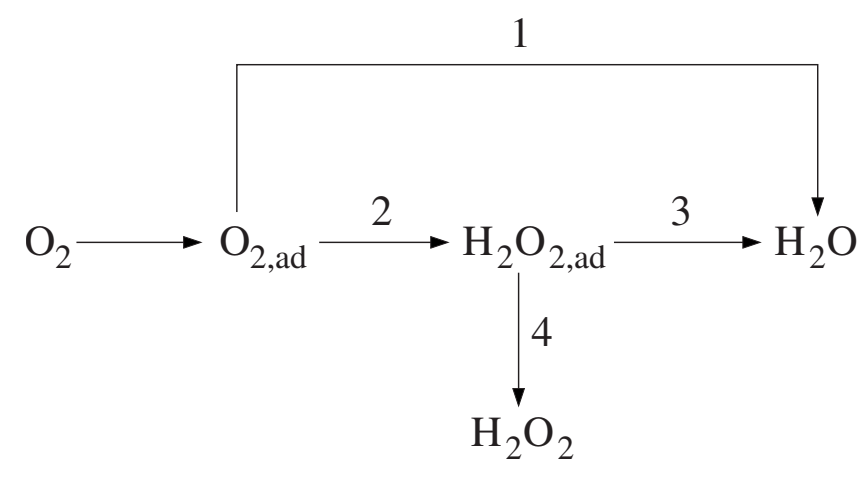

Figure 2. The model of Damjanovic et al. for oxygen reduction on metals in both alkaline and acidic media. Water can either be formed directly via the four-electron pathway, 1, or via the two-electron pathway, 2 and 3 in series. ${ }^{40}$ The subscript "ad" refers to an adsorbed species.

hydrogen oxidation reaction (HOR), are reviewed. The ORR, in particular, is highly complex and leads to the formation of intermediates that are harmful to the membrane.

At the cathode, $\mathrm{O}_{2}$ is reduced to water either through a fourelectron path or through a two-electron path with intermediate radical and $\mathrm{H}_{2} \mathrm{O}_{2}$ formation (in an acidic medium). This model, originally proposed by Damjanovic et al., ${ }^{40}$ is depicted in Fig. 2, where the subscript "ad" denotes an adsorbed species. Several similar models have been proposed, notably those of Wroblowa et al. ${ }^{41}$ and Appleby. ${ }^{42}$ Step 1 in Fig. 2 is the four-electron (direct) reduction path $[1.229 \mathrm{~V}$ vs standard hydrogen electrode (SHE)]. Reactions 2 and 3 represent a series path where $\mathrm{O}_{2}$ is first reduced to $\mathrm{H}_{2} \mathrm{O}_{2}$ through two-electron transfer ( $0.695 \mathrm{~V}$ vs SHE), followed by reduction of $\mathrm{H}_{2} \mathrm{O}_{2}$ to $\mathrm{H}_{2} \mathrm{O}$ (1.77 V vs SHE). $\mathrm{H}_{2} \mathrm{O}_{2}$ can also detach from the catalyst surface and enter the bulk (Reaction 4). The two pathways occur simultaneously in varying ratios; the four-electron pathway is the dominant mechanism on noble metals such at Pt, whereas the two-electron pathway is favored on most carbons.

The differences between the reduction models proposed by Damjanovic et al., Wroblowa et al., Appleby, and others concern the interaction of intermediates, the nature of $\mathrm{O}_{2}$ adsorption (bonding on the catalyst), and the individual steps required to reach the final product. ${ }^{43}$ It is possible to fit distinct models to the same experimental data. Intermediates such as the radicals $\cdot \mathrm{OH}, \cdot \mathrm{OOH}$, and superoxide are known to exist, but the precise mechanism on any given catalyst remains elusive. ${ }^{4}$ Insight into the likelihood of possible pathways can, however, come from quantum chemistry calculations based on density functional theory (DFT) and ab initio molecular dynamics. ${ }^{45}$ The stability of intermediates and the activation energies for proposed individual steps can be approximately calculated. ${ }^{46}$ Assuming $\mathrm{O}_{2}$ adsorption at a dual site, Sidik and Anderson ${ }^{47}$ demonstrated by DFT that the rate-determining step is $\mathrm{Pt}-\mathrm{O}_{2}+\mathrm{H}^{+}+\mathrm{e}^{-} \rightarrow \mathrm{Pt}-\mathrm{OOH}$, in agreement with selected experimental data. ${ }^{42,48}$ DFT calculations have also demonstrated that $\mathrm{H}_{2} \mathrm{O}_{2}$ is generally unstable on low-index platinum, dissociating into two adsorbed $\cdot \mathrm{OH}$ radicals. ${ }^{49}$ This result seems to be at odds with the appreciable quantities of $\mathrm{H}_{2} \mathrm{O}_{2}$ produced on supported platinum catalysts, including $\mathrm{Pt}(100), \mathrm{Pt}(110)$, and $\mathrm{Pt}(111)$, in rotating ringdisk electrode studies, ${ }^{50}$ particularly in the presence of a few ppm of $\mathrm{Cl}^{-}$. Moreover, $\mathrm{H}_{2} \mathrm{O}_{2}$ has been detected both in the exhaust stream and within the membrane of a fuel cell. ${ }^{23,39}$ It is clear that some $\mathrm{H}_{2} \mathrm{O}_{2}$ detaches from the catalyst surface in the presence of water. Indeed, the two-electron transfer (step 2 with the desorption step 4 in Fig. 2) has been investigated by several researchers and is reported to occur at a potential of $0.695 \mathrm{~V}$ vs $\mathrm{SHE}^{29,39,51}$

$$
\mathrm{O}_{2}+2 \mathrm{H}^{+}+2 \mathrm{e}^{-} \rightleftharpoons \mathrm{H}_{2} \mathrm{O}_{2}
$$

The reaction constants and activation energy have been estimated by Sethuraman et al. ${ }^{29}$ 
The HOR in the anode proceeds via one of two mechanisms, depending on the catalyst. ${ }^{52,53}$ The Tafel-Volmer pathway consists of a dissociative chemisorption step, followed by two singleelectron oxidations of the $\mathrm{H}$ adatoms

$$
\begin{gathered}
\mathrm{H}_{2} \rightarrow 2 \mathrm{Pt}-\mathrm{H} \quad \text { Tafel reaction } \\
\mathrm{Pt}-\mathrm{H} \rightleftharpoons \mathrm{H}^{+}+\mathrm{e}^{-}+\mathrm{Pt} \quad \text { Volmer reaction }
\end{gathered}
$$

The Heyrovsky-Volmer pathway consists of a single-electron oxidation and simultaneous chemisorption, followed by a singleelectron oxidation of the $\mathrm{H}$ adatom

$$
\mathrm{H}_{2} \rightleftharpoons \mathrm{Pt}-\mathrm{H}+\mathrm{e}^{-}+\mathrm{H}^{+} \quad \text { Heyrovsky reaction }
$$

Recent DFT studies have suggested that the HOR in acid solution follows the Tafel-Volmer mechanism on Pt surfaces, ${ }^{54,55}$ except on Pt(100) at low overpotentials. ${ }^{56}$ However, Zhang et al. have suggested a mixed Tafel-Heyrovsky-Volmer mechanism for platinum electrodes in PEM fuel cells with the Heyrovsky-Volmer pathway dominating at high overpotentials and the Tafel-Volmer pathway at low overpotentials. ${ }^{53}$

At the anode, it is believed that $\mathrm{H}_{2} \mathrm{O}_{2}$ forms from hydrogen radicals produced by the Volmer reaction, and $\mathrm{O}_{2}$, which can cross the membrane from the cathode $16,23,26,57$

$$
\begin{gathered}
\mathrm{H} \cdot+\mathrm{O}_{2} \rightarrow \cdot \mathrm{OOH} \\
\cdot \mathrm{OOH}+\mathrm{H} \cdot \rightarrow \mathrm{H}_{2} \mathrm{O}_{2}
\end{gathered}
$$

The rate constants of these (chemical) reactions have been estimated. ${ }^{58,59}$

The predominant mechanisms for $\mathrm{H}_{2} \mathrm{O}_{2}$ generation are unclear. Although conditions generally favor production at the anode,${ }^{60}$ preferential degradation has been reported at both the anode and cathode. $^{11}$

Radical formation. - $\cdot \mathrm{OH}$ radicals are formed during ORR on platinum and bind strongly with the platinum surface ${ }_{51,62}$ in the work of Markovic et al., ${ }^{50}$ cyclic voltammograms using $\mathrm{Pt}(111)$ electrodes exhibit an onset potential for adsorbed $\cdot \mathrm{OH}$ formation at approximately $0.6 \mathrm{~V}$ vs SHE. Anderson proposed that the radical is formed predominantly from the oxidation of bonded water. ${ }^{46,63} \mathrm{In}$ the presence of water, a small fraction of the radicals may detach from the electrocatalyst surface and, provided they do not recombine or undergo other reactions, attack the ionomer/membrane. However, it is likely that trace amounts of transition-metal ions found in the membrane/ionomer are the main source of radicals, as was proposed by Laconti et al. ${ }^{23,64}$ These ions, $\mathrm{M}^{2+}$, where $\mathrm{M}=\mathrm{Fe}, \mathrm{Cu}$, or $\mathrm{Mg}$ (among others), can arise from the manufacturing process or can evolve during operation, from, for example, the end plates. ${ }^{25,65,66}$ Pozio demonstrated that a fuel cell with stainless steel plates was significantly degraded after $960 \mathrm{~h}$ of continuous operation. ${ }^{25}$ When the stainless steel plates were replaced with iron-free, aluminumalloy plates, little or no degradation was observed over a further 1200 h. Aoki et al., ${ }^{34}$ Merlo et al., ${ }^{38}$ and Inaba et al. ${ }^{36}$ have all shown that membrane degradation is negligible without reactant crossover, particularly $\mathrm{O}_{2}$, which suggests that radicals generated from ORR are not a significant contributor to degradation. It is also known that the degradation rate increases with decreasing $\mathrm{RH},{ }^{16,17,67}$ for which a decreasing number of radicals would be expected to detach from the catalyst surface.

Transition-metal ions can be highly effective catalysts for the breakdown of peroxide to radicals through the well-known Fenton (catalyzed Haber-Weiss) reactions ${ }^{68}$

$$
\begin{gathered}
\mathrm{M}^{2+}+\mathrm{H}_{2} \mathrm{O}_{2} \rightarrow \mathrm{M}^{3+}+\cdot \mathrm{OH}+\mathrm{OH}^{-} \\
\mathrm{M}^{3+}+\mathrm{H}_{2} \mathrm{O}_{2} \rightarrow \mathrm{M}^{2+}+\cdot \mathrm{OOH}+\mathrm{H}^{+} \\
\mathrm{M}^{3+}+\cdot \mathrm{OOH} \rightarrow \mathrm{M}^{2+}+\mathrm{H}^{+}+\mathrm{O}_{2} \\
\mathrm{H}_{2} \mathrm{O}_{2}+\cdot \mathrm{OH} \rightarrow \cdot \mathrm{OOH}+\mathrm{H}_{2} \mathrm{O}
\end{gathered}
$$

$$
\begin{gathered}
\mathrm{M}^{3+}+\mathrm{e}^{-} \rightarrow \mathrm{M}^{2+} \text { cathode } \\
\mathrm{M}^{2+}+\cdot \mathrm{OH} \rightarrow \mathrm{M}^{3+}+\mathrm{OH}^{-} \\
\mathrm{M}^{2+}+\mathrm{H}^{+}+\cdot \mathrm{OOH} \rightarrow \mathrm{M}^{3+}+\mathrm{H}_{2} \mathrm{O}_{2}
\end{gathered}
$$

where $\mathrm{M}$ is the metal ion. More details on the Fenton mechanism can be found in the work of Haber and Weiss ${ }^{68}$ and Barb et al. ${ }^{69}$ The efficiency with which radicals are produced in the above reactions is the basis of the so-called Fenton test. ${ }^{15,23,27,28}$

Membrane attack mechanisms. - The highly unstable radicals generated by the sequence of reactions described above eventually attack the PFSA membrane structure. Several modes of attack have been proposed, the most cited of which was put forward by Curtin et al., ${ }^{22}$ supported by measurements of the fluoride emission rate (FER) $)^{12,15,23,28,70}$

$$
\begin{gathered}
R_{\mathrm{p}}-\mathrm{CF}_{2} \mathrm{COOH}+\cdot \mathrm{OH} \rightarrow R_{\mathrm{p}}-\mathrm{CF}_{2} \cdot \mathrm{CO}_{2}+\mathrm{H}_{2} \mathrm{O} \\
R_{\mathrm{p}}-\mathrm{CF}_{2}+\cdot \mathrm{OH} \rightarrow R_{\mathrm{p}}-\mathrm{CF}_{2} \mathrm{OH} \\
R_{\mathrm{p}}-\mathrm{CF}_{2} \mathrm{OH} \rightarrow R_{\mathrm{p}}-\mathrm{COF}+\mathrm{HF} \\
R_{\mathrm{p}}-\mathrm{COF}+\mathrm{H}_{2} \mathrm{O} \rightarrow R_{\mathrm{p}}-\mathrm{COOH}+\mathrm{HF}
\end{gathered}
$$

The reaction sequence begins with abstraction of hydrogen and formation of a perfluorocarbon radical. This radical reacts with an hydroxyl radical to form HF and an acid fluoride; the final step is the hydrolysis of the acid fluoride. Direct testing of model compounds and stabilized membranes has confirmed that carboxylic acid end groups, $\mathrm{COOH}$, are the main $\mathrm{H}$-containing end groups to initiate this mode of degradation. ${ }^{22,38}$ They are adopted in this work as representative of weak end groups.

$-\mathrm{COOH}$ groups can be formed during the polymerization process or from the transformation of other nonperfluorinated end groups via radical attack ${ }^{21,23,27}$

$$
R_{\mathrm{p}}-\mathrm{CF}_{2} \mathrm{CF}_{2} Y+\cdot \mathrm{OH} \rightarrow R_{\mathrm{p}}-\mathrm{CF}_{2} \mathrm{COOH}
$$

where $Y$ is the nonperfluorinated end group, such as $\mathrm{CHF}_{2}$.

From the analysis of effluent water under membrane degradation test conditions, several research groups ${ }^{12,15,27,33}$ have reported the presence of the molecule perfluoro(3-oxa-5-methyl)pentane-1sulfonic-5-carboxylic diacid, $\mathrm{HOOC}-\mathrm{CF}\left(\mathrm{CF}_{3}\right)-\mathrm{O}-\mathrm{CF}_{2} \mathrm{CF}_{2}-\mathrm{SO}_{3} \mathrm{H}$. The existence of this molecule, which is termed "molecule A" following Xie and Hayden, ${ }^{27}$ can be explained by side-chain cleavage from the polymer when the main unzipping mechanism (Reaction 7) approaches a junction with a side chain

$$
R_{\mathrm{p}}-\mathrm{CFOOH}-\mathrm{S}+\cdot \mathrm{OH} \rightarrow R_{\mathrm{p}}-\mathrm{COOH}+\mathrm{A}+\mathrm{HF}+\mathrm{CO}_{2}
$$

where $\mathrm{S}$ represents a side chain and A represents molecule A. The formula and structure of both are shown in Fig. 3. Molecule A can diffuse through the membrane and undergo an independent degradation reaction as follows

$$
A+2 \cdot \mathrm{OH} \rightarrow 2 \mathrm{HF}+2 \mathrm{CO}_{2}+\mathrm{SO}_{4}^{2-}
$$

The justification for Reaction 7 is based on fluoride-ion measurements. A plot of fluoride-ion generation against carboxylic acid content (in Nafion), however, exhibits a nonzero intercept ${ }^{33}$ suggesting that up to $10 \%$ of the fluoride is generated from a mechanism other than Reaction 7. There is much speculation regarding the origins of this relatively small percentage of the total fluoride-ion emission, with no definitive conclusions.

From X-ray photoelectron spectroscopy analysis, Chen et al. ${ }^{28}$ claimed strong evidence for $\mathrm{CF}_{2}$ decomposition on the polymer backbone, possibly arising from radical attack on defects such as $\mathrm{C}-\mathrm{H}$ and $\mathrm{C}=\mathrm{C}$ bonds to form carbon-centered radicals. These carbon-centered radicals are then assumed to undergo reaction with hydroxyl or $\mathrm{O}_{2}$ and water to produce fluoride ions and polymer fragments, presumably with $-\mathrm{COOH}$ groups attached. The authors 
Nafion side chain<smiles>OC(F)C(F)(OC(F)(F)C(F)(F)F)C(F)(F)F</smiles>

Figure 3. Formula and structure of (i) the Nafion side-chain molecule and (ii) molecule $\mathrm{A}$.

also suggest a second, minor mechanism driven by radical and peroxide attack of $-\mathrm{SO}_{3}$ groups to form cross-linking S-O-S bonds, which are assigned to weak signals detected in Fourier transform infrared spectra. This anhydride may react with an $-\mathrm{SO}_{3}$ group to produce sulfonate esters, which in turn can undergo reaction with water to form carboxylic acid. Both mechanisms are plausible, but much of the evidence presented for the main mechanism can equally be explained by the mechanism of Curtin et al. (Reaction 7).

Mittal et al. ${ }^{71}$ tested Nafion membranes that had been converted into different cationic forms by immersion in $\mathrm{NaOH}, \mathrm{CsCO}_{3}$, or $\mathrm{LiCl}$ solution $\left(-\mathrm{SO}_{3} \mathrm{H}\right.$ is replaced with $-\mathrm{SO}_{3} \mathrm{M}$, with $\mathrm{M}=\mathrm{Na}$, Cs, or $\mathrm{Li}$ ). The FERs from these modified membranes were 2 orders of magnitude lower than the FERs from Nafion in the $\mathrm{H}^{+}$form, suggesting that $-\mathrm{SO}_{3}$ groups play a key role in the degradation of Nafion membranes. These results contradict those of Chen et al., ${ }^{28}$ which imply that $-\mathrm{SO}_{3}$ groups play only a minor role in the degradation process. The probable explanation is ion exchange of $\mathrm{COOH}$ acid groups to COOM during the immersion process (as Mittal et al. conceded was likely to occur in their experiments).

Schlick and co-workers investigated the degradation of Nafion and Dow membranes using UV irradiation and electron spin resonance (ESR) ${ }^{72,73}$ They detected the presence of the chain-end radicals $R_{\mathrm{p}}-\mathrm{OCF}_{2} \mathrm{CF}_{2} \cdot{ }^{1 / 2}$ As the irradiation time increased, the ESR signal intensity corresponding to these radicals increased, while the $\mathrm{Fe}(\mathrm{III})$ intensity decreased. Weak signals were detected even in the absence of $\mathrm{H}_{2} \mathrm{O}_{2}$ if the membranes were neutralized with $\mathrm{Fe}$ (III). They concluded that $\mathrm{Fe}(\mathrm{III})$ may facilitate the UV scission of $\mathrm{C}-\mathrm{S}$ bonds in the side chains or engender redox reaction

$$
\mathrm{Fe}(\mathrm{III})+R_{\mathrm{p}}-\mathrm{OCF}_{2} \mathrm{CF}_{2} \mathrm{SO}_{3}^{-} \rightarrow \mathrm{Fe}(\mathrm{II})+R_{\mathrm{p}}-\mathrm{OCF}_{2} \mathrm{CF}_{2} \mathrm{SO}_{3} \text {. }
$$

The $R_{\mathrm{p}}-\mathrm{OCF}_{2} \mathrm{CF}_{2} \mathrm{SO}_{3}$. radicals then recombine to form $R_{\mathrm{p}}$ - $\mathrm{OCF}_{2} \mathrm{CF}_{2}, \mathrm{SO}_{2}$, and $\mathrm{O}_{2}$. For neutralization with both $\mathrm{Cu}(\mathrm{II})$ and $\mathrm{Fe}(\mathrm{II})$, quintet signals were detected in the ESR spectra and assigned to the radical $-\mathrm{CF}_{2} \mathrm{C} \cdot(\mathrm{OR})-\mathrm{CF}_{2}-$. On the basis of this finding, the authors proposed that the backbone carbon atoms linked to the side chains are attacked, releasing fluorine. It is not clear, however, to what extent these results are affected by photoexcitation of the membranes; without UV irradiation, the signal intensity corresponding to the chain-end radicals is weak, and the rate of formation of these radicals may well be negligible within a fuel cell.

In summary, the model developed in this work incorporates the most widely accepted routes to $\mathrm{H}_{2} \mathrm{O}_{2}$ and radical production and the most commonly cited chemical-degradation mechanism. Other mechanisms can be included, but it is natural to focus on that of

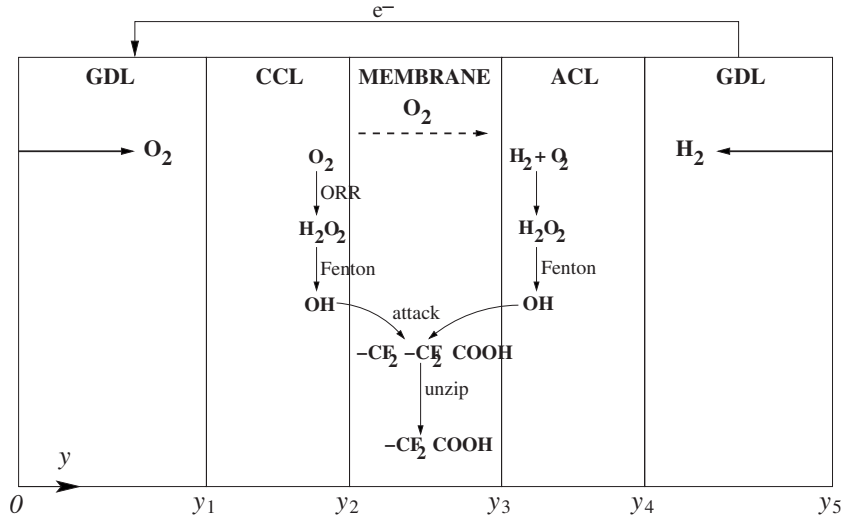

Figure 4. A schematic of the MEA and definitions of the positions along the thickness coordinate $y$. A schematic of the peroxide/radical formation, backbone unzipping, and side-chain cleavage is also shown.

Curtin et al. as a first step in an heirarchical approach. For clarity, the mechanisms considered are Reactions $1-10$, together with the four-electron transfer mechanism for $\mathrm{O}_{2}$ reduction

$$
\mathrm{O}_{2}+4 \mathrm{H}^{+}+4 \mathrm{e}^{-} \rightleftharpoons 2 \mathrm{H}_{2} \mathrm{O}
$$

The following (global) version of Reaction 7 is assumed for the purposes of simulation

$$
R_{\mathrm{p}}-\mathrm{CF}_{2} \mathrm{COOH}+2 \cdot \mathrm{OH} \rightarrow R_{\mathrm{p}}-\mathrm{COOH}+\mathrm{CO}_{2}+2 \mathrm{HF}
$$

\section{Model Equations}

The main features and underlying assumptions of the model are described below. The reader is referred to earlier work ${ }^{74-77}$ for further details of the standard conservation principles.

Assumptions.—Domain.—The domain includes the entire MEA, shown in Fig. 4. Each component is modelled explicitly. Where convenient, the following notation is used: GDL is the gas diffusion layer, CCL is the cathode catalyst layer, ACL is the anode catalyst layer, and CL is the catalyst layer.

CL.- The primary carbon particles of the catalyst carbon support form spherical clusters, termed aggregates. The aggregates are held together by van der Waals forces to form agglomerates, which are assumed to be surrounded by electrolyte and water layers. The pores between the agglomerates are referred to as "primary pores," which are distinct from the smaller pores between the carbon particles. Sufficient contact between the agglomerates to permit electron and proton migration is further assumed. Reaction occurs on the agglomerate surfaces.

Reactant mass transport and transfer.- A distinction is made between reactants in the gas and dissolved phases. Given the requirement of simultaneous electrolyte and catalyst contact, the reaction is assumed to occur in the dissolved phase. The gas-phase species are transported by convection and diffusion and the dissolved species by diffusion alone. Deviations from Henry's law provide the driving force for interfacial mass transfer between the two phases. It is assumed that $\mathrm{H}_{2} \mathrm{O}_{2}, \cdot \mathrm{OH}$, and $\cdot \mathrm{OOH}$ are in the dissolved phase at the reaction locations and that $\mathrm{HF}$ is produced in the dissolved phase. The concentrations of carbon dioxide and $\mathrm{OH}^{-}$are neglected, because they do not participate in the degradation scheme selected and justified above.

Charge.-Electroneutrality and a pseudo-steady state apply to conservation of charge, as justified in Wang and Wang. ${ }^{78}$

Water.-Water is considered to exist in three forms, namely, as a dissolved species in the membrane/electrolyte, as vapor, and as liquid. The net water produced is in liquid form. Mass transfer between the phases is dictated by deviations from appropriate equilibria, as described below. 
Table I. Gas-phase diffusion and convection parameters.

\begin{tabular}{|c|c|c|}
\hline Symbol & Quantity & Size \\
\hline$\sigma_{\mathrm{O}_{2}}$ & $\mathrm{O}_{2}$ Lennard-Jones constant ${ }^{81}$ & $3.433 \AA$ \\
\hline$\sigma_{\mathrm{H}_{2}}$ & $\mathrm{H}_{2}$ Lennard-Jones constant ${ }^{81}$ & $2.915 \AA$ \\
\hline$\sigma_{\text {vapor }}$ & Vapor Lennard-Jones constant ${ }^{81}$ & $2.903 \AA$ \\
\hline$\sigma_{\mathrm{N}_{2}}$ & $\mathrm{~N}_{2}$ Lennard-Jones constant ${ }^{81}$ & $3.667 \AA$ \\
\hline$\Omega_{\mathrm{N} O} \mathrm{O}_{2}$ & $\mathrm{O}_{2}-\mathrm{N}_{2}$ collision integral ${ }^{81}$ & 0.966 \\
\hline$\Omega_{\mathrm{N}_{2}, \mathrm{H}_{2}}$ & $\mathrm{H}_{2}-\mathrm{N}_{2}$ collision integral ${ }^{81}$ & 0.848 \\
\hline$\Omega_{\mathrm{N}_{2}, \text { vapor }}$ & Vapor- $\mathrm{N}_{2}$ collision integral ${ }^{81}$ & 1.305 \\
\hline$\Omega_{\mathrm{N}_{2}, \mathrm{~N}_{2}}$ & $\mathrm{~N}_{2}-\mathrm{N}_{2}$ collision integral $^{81}$ & 0.949 \\
\hline$D_{\mathrm{H}_{2} \mathrm{O}_{2}}$ & $\mathrm{H}_{2} \mathrm{O}_{2}$ diffusion coefficient & $1.89 \times 10^{-5} \mathrm{~m}^{2} \mathrm{~s}^{-1}$ \\
\hline$D_{\mathrm{HF}}$ & Assumed HF diffusion coefficient & $10^{-5} \mathrm{~m}^{2} \mathrm{~s}^{-1}$ \\
\hline$D_{\mathrm{OH}}$ & OH diffusion coefficient $/ \mathrm{H}_{2} \mathrm{O}$ at $60^{\circ} \mathrm{C}, 300 \mathrm{kPa}$ & $2.08 \times 10^{-5} \mathrm{~m}^{2} \mathrm{~s}^{-1}$ \\
\hline$\kappa_{\mathrm{G}}$ & Absolute permeability of diffusion layers ${ }^{109}$ & $8.69 \times 10^{-12} \mathrm{~m}^{2}$ \\
\hline$\kappa_{\mathrm{C}}$ & Absolute permeability of CLs ${ }^{110}$ & $1.02 \times 10^{-12} \mathrm{~m}^{2}$ \\
\hline$\mu$ & Gas-phase dynamic viscosity in CCL/air at $60^{\circ} \mathrm{C}$ & $2.01 \times 10^{-5} \mathrm{~Pa} \mathrm{~s}$ \\
\hline
\end{tabular}

Kinetics.- As a first approximation, it is assumed that (i) Reactions 1 and 4-10 are irreversible and (ii) the concentration of $\mathrm{M}^{2+}$ is constant and uniform, with only the main Fenton reaction (Reaction 6a) considered. In real scenarios, the rate of radical production depends on the rate at which ions are added to the system, which is a function of material properties, particularly of the plates, and the operating conditions. A constant $\mathrm{M}^{2+}$ concentration is representative of test scenarios, such as the Fenton, and similar, accelerated degradation experiments. A finite rate of ion addition introduces several additional control parameters associated with the Fenton mechanism, the effects of which are explored in detail in a forthcoming paper. It is further assumed that molecule A remains in the electrolyte phase.

Material property variations.- The variation of material and structural properties as a result of degradation, ${ }^{19,79,80}$ the interaction of degradation and platinum sintering, ${ }^{24}$ and carbon oxidation due to reactant crossover ${ }^{9,10}$ are not incorporated in the model. It would not be feasible to include these additional processes in the present study due to the complex nature of the interactions and the difficulties posed in separating out the effects associated with individual phenomena. There are, moreover, few characterizations of the variations in properties. The focus in this paper is placed on appraising membrane-degradation mechanisms, which can be achieved in a qualitative sense. The attendant consequences of degradation and any possibly related phenomena are worthy of study in isolation.

Principles of conservation.-Reactant mass balance.- Massbalance equations in the gas phase can be derived by taking into account transport by diffusion and convection together with mass transfer to and from the electrolyte

$$
\begin{gathered}
\frac{\partial}{\partial t}\left[\epsilon(1-s) c_{i}\right]-\frac{\partial}{\partial y}\left[\epsilon^{3 / 2}(1-s)^{3 / 2} D_{i} \frac{\partial c_{i}}{\partial y}-v_{\mathrm{g}} c_{i}\right]=-S_{\mathrm{g}, i} \\
\frac{\partial}{\partial t}\left[\epsilon(1-s) c_{\mathrm{H}_{2} \mathrm{O}}^{v}\right]-\frac{\partial}{\partial y}\left[\epsilon^{3 / 2}(1-s)^{3 / 2} D_{\mathrm{H}_{2} \mathrm{O}}^{v} \frac{\partial c_{\mathrm{H}_{2} \mathrm{O}}}{\partial y}-v_{\mathrm{g}} c_{\mathrm{H}_{2} \mathrm{O}}^{v}\right] \\
=S_{\mathrm{g} \leftrightarrow 1}+v S_{\mathrm{d} \leftrightarrow \mathrm{g}}
\end{gathered}
$$

where $s$ denotes liquid-water saturation; $c_{\mathrm{i}}$ and $c_{\mathrm{H}_{2} \mathrm{O}}^{v}$ denote the pore concentrations of species, $i=\mathrm{O}_{2}, \mathrm{H}_{2}, \mathrm{~N}_{2}, \mathrm{H}_{2} \mathrm{O}_{2}, \cdot \mathrm{OH}$, $\cdot \mathrm{OOH}$, and $\mathrm{HF}$ and water vapor, respectively; $c_{i}^{\mathrm{d}}$ is the concentration of species $i$ dissolved in the electrolyte and membrane; $D_{i}$ is the free-space diffusion coefficient of species $i$ in the pore space and $D_{\mathrm{H}_{2} \mathrm{O}}^{v}$ is the free-space diffusion coefficient for water vapor; and $\epsilon$ is the porosity, which takes the value $\epsilon=\epsilon_{\mathrm{p}}$ in the CLs and $\epsilon=\epsilon_{\mathrm{G}}$ in the GDLs. The diffusion coefficients are approximated by the ChapmanEnskog formula, ${ }^{81}$ assuming $\mathrm{N}_{2}$ as the dominating component in both electrodes

$$
D_{i}=0.01858 \frac{T^{3 / 2}}{p_{\mathrm{g}}} \frac{\sqrt{1 / M_{i}+1 / M_{\mathrm{N}_{2}}}}{\sigma_{i \mathrm{~N}_{2}}^{2} \Omega_{i \mathrm{~N}_{2}}}
$$

in $\mathrm{m}^{2} \mathrm{~s}^{-1}$, where $T$ is temperature and $p_{\mathrm{g}}$ is the gas pressure. For each species $i, M_{i}$ is the molar mass, $\sigma_{i \mathrm{~N}_{2}}$ is the Lennard-Jones force constant, and $\Omega_{i \mathrm{~N}_{2}}$ is the collision integral. The Lennard-Jones constants can be approximated by $\sigma_{\mathrm{N}_{2}, i}=\left(\sigma_{i}+\sigma_{\mathrm{N}_{2}}\right) / 2$, where $\sigma_{i}$ are the Lennard-Jones constants for the individual species $i$ (Table I). The diffusion coefficients for $\mathrm{H}_{2} \mathrm{O}_{2}$ and $\mathrm{HF}$ are taken as constant, and their values are given in Table I. The value for $\cdot \mathrm{OH}$ was approximated by the value for vapor, which has been shown by Bertram et al. to provide a good fit. ${ }^{82}$ In Eq. 13 and 14, the free-space diffusion coefficients are multiplied by the void fraction raised to the power $3 / 2$ to obtain their effective values (Bruggeman correction). The gas velocity follows Darcy's law

$$
v_{\mathrm{g}}=-\frac{\kappa}{\mu}(1-s)^{3} \frac{\partial p_{\mathrm{g}}}{\partial y}
$$

where $\kappa$ is the absolute permeability of the medium $\left(\kappa=\kappa_{\mathrm{G}}\right.$ in the GDLs and $\kappa=\kappa_{C}$ in the CLs) and $\mu$ is the dynamic viscosity of the gas.

The source term $S_{\mathrm{g}, i}$ (defined in Table II) is the rate of mass transfer between the electrolyte and gas phases for species $i, S_{\mathrm{g} \leftrightarrow 1}$ is the rate of condensation/evaporation, and $S_{\mathrm{d} \leftrightarrow \mathrm{g}}$ is the rate of mass transfer of water between the dissolved and gas phases. The quantity $v$ is the fixed-charge site concentration of the membrane. In Table II, $k_{\mathrm{m}, i}$ are volumetric mass-transfer coefficients from the gas to the electrolyte/water phase on the gas side, and $H_{i}$ are dimensionless Henry constants. The $k_{\mathrm{m}, i}$ are evaluated using a formula for flow past a spherical particle based on a local Sherwood number of 2: $k_{\mathrm{m}, i}=a_{\mathrm{ag}} 2 D_{i} / d_{\mathrm{C}}$, where $a_{\mathrm{ag}}$ is the specific surface area of the agglomerates and $d_{\mathrm{C}}$ is the average pore diameter in the CLs (characteristic length scale) ${ }^{81}$ The Henry's law coefficients for $\mathrm{H}_{2} \mathrm{O}_{2}, \mathrm{HF}$, and $\cdot \mathrm{OH}$ shown in Table III were approximated by the values for air-water systems at $60^{\circ} \mathrm{C}$. The condensation/evaporation coefficient $k_{\mathrm{g} \leftrightarrow 1}$ is defined below.

Table II. Sources and sinks for the gas-phase equations (Eq. 13 and 14). These terms represent, from top to bottom, reactant dissolution into the electrolyte, condensation/evaporation, and vapor/dissolved water mass transfer.

\begin{tabular}{lccc} 
Term & ACL & CCL & GDL \\
\hline$S_{\mathrm{g}, i}$ & $k_{\mathrm{m}, i}\left(H_{i} c_{i}-c_{i}^{\mathrm{d}}\right)$ & $k_{\mathrm{m}, i}\left(H_{i} c_{i}-c_{i}^{\mathrm{d}}\right)$ & 0 \\
$S_{\mathrm{g} \leftrightarrow 1}$ & $-k_{\mathrm{g} \leftrightarrow(}\left(x_{\mathrm{v}} p_{\mathrm{g}}-p_{\mathrm{sat}}\right)$ & $-k_{\mathrm{g} \leftrightarrow l}\left(x_{\mathrm{v}} p_{\mathrm{g}}-p_{\mathrm{sat}}\right)$ & $-k_{\mathrm{g} \leftrightarrow l}\left(x_{\mathrm{v}} p_{\mathrm{g}}-p_{\mathrm{sat}}\right)$ \\
$S_{\mathrm{d} \leftrightarrow \mathrm{g}}$ & $k_{\mathrm{d} \leftrightarrow \mathrm{g}}\left(c_{\mathrm{H}_{2} \mathrm{O}}^{\mathrm{O}}-c_{\mathrm{H}_{2} \mathrm{O}}^{*}\right)$ & $k_{\mathrm{d} \leftrightarrow \mathrm{g}}\left(c_{\mathrm{H}_{2} \mathrm{O}}-c_{\mathrm{H}_{2} \mathrm{O}}^{*}\right)$ & 0
\end{tabular}


Table III. Default parameter values related to mass transfer.

\begin{tabular}{|c|c|c|}
\hline Symbol & Quantity & Size \\
\hline$H_{\mathrm{O}_{2}}$ & $\mathrm{O}_{2}$ Henry's law constant ${ }^{112}$ & 0.15 \\
\hline$H_{\mathrm{H}_{2}}$ & $\mathrm{H}_{2}$ Henry's law constant ${ }^{113}$ & 0.63 \\
\hline$H_{\mathrm{H}_{2} \mathrm{O}_{2}}$ & $\mathrm{H}_{2} \mathrm{O}_{2}$ Henry's law constant/liquid water at $60^{\circ} \mathrm{C}{ }^{114}$ & $3.04 \times 10^{7}$ \\
\hline$H_{\mathrm{HF}}$ & HF Henry's law constant/liquid water at $60^{\circ} \mathrm{C}^{115}$ & 3515 \\
\hline$H_{\mathrm{OH}}$ & $\cdot \mathrm{OH}$ Henry's law constant/liquid water at $60^{\circ} \mathrm{C}^{116}$ & 3951 \\
\hline$k_{\mathrm{des}, 1}$ & $\mathrm{H}_{2} \mathrm{O}$ desorption coefficient ${ }^{74}$ & 100 \\
\hline$k_{\mathrm{ads}, 1}$ & $\mathrm{H}_{2} \mathrm{O}$ adsorption coefficient ${ }^{74}$ & 10 \\
\hline$k_{\text {des,g }}$ & Desorption constant ${ }^{91}$ & $3.3 \times 10^{-6} \mathrm{~m} \mathrm{~s}^{-1}$ \\
\hline$k_{\text {evap }}$ & Evaporation coefficient $^{117}$ & $100 \mathrm{~s}^{-1} \mathrm{~atm}^{-1}$ \\
\hline$k_{\text {cond }}$ & Condensation coefficient ${ }^{117}$ & $100 \mathrm{~s}^{-1}$ \\
\hline
\end{tabular}

The electrolyte volume fraction, $\epsilon_{\mathrm{e}}$, has two components; one originates from the films that coat the agglomerates $\left(\epsilon_{\mathrm{e}}^{\mathrm{f}}\right)$, while the other is derived from the electrolyte contained in the agglomerate interiors $\left(\epsilon_{\mathrm{e}}^{i}\right)$, with $\epsilon_{\mathrm{e}}=\epsilon_{\mathrm{e}}^{\mathrm{f}}+\epsilon_{\mathrm{e}}^{i}$. Swelling is accounted for through the relationship $\epsilon_{\mathrm{e}}^{\mathrm{f}}=\epsilon_{\mathrm{e}, 0}^{\mathrm{f}}+0.0126 \lambda$, where $\lambda$ is the membrane water content and $\epsilon_{\mathrm{e}, 0}^{\mathrm{f}}$ represents the volume fraction of electrolyte films without any swelling. More detail is provided in the Kinetics section. Mass balances for species $i=\mathrm{O}_{2}, \mathrm{H}_{2}, \mathrm{H}_{2} \mathrm{O}_{2}, \cdot \mathrm{OH}$, $\cdot \mathrm{OOH}$, HF, and molecule $\mathrm{A}$ dissolved in the electrolyte can be expressed as follows

$$
\frac{\partial}{\partial t}\left(\epsilon c_{i}^{\mathrm{d}}\right)-\frac{\partial}{\partial y}\left(\epsilon^{3 / 2} D_{i}^{\mathrm{d}} \frac{\partial c_{i}^{\mathrm{d}}}{\partial y}\right)=S_{i}+ \begin{cases}0 & \text { membrane }(\epsilon=1) \\ S_{\mathrm{g}, i} & \text { CLs }\left(\epsilon=\epsilon_{\mathrm{e}}\right)\end{cases}
$$

where $D_{i}^{\mathrm{d}}$ are the free-space diffusion coefficients in the electrolyte. The source terms $S_{i}$ are defined in Table IV and are the rates of consumption or generation of species $i$. In Table IV, $q_{11}$ is the rate of $\mathrm{O}_{2}$ reduction in the cathode and $q_{1}-q_{10}$ are the rates of Reactions $1-10$. The forms of these reaction rates are presented in the Kinetics section.

The $\mathrm{O}_{2}$ diffusion coefficient through Nafion was correlated by Sethuraman et al. ${ }^{29}$ across a range of temperature and water activity, $a_{\mathrm{w}}$

$$
D_{\mathrm{O}_{2}}^{\mathrm{d}}=9.78 \times 10^{-12}+3.5 \times 10^{-13} T+10^{-8} a_{\mathrm{w}} \text { in } \mathrm{m}^{2} \mathrm{~s}^{-1}
$$

The remaining diffusion coefficients were approximated by the values in liquid water using the correlation developed by Wilke and Chang 83

$$
D_{i}^{\mathrm{d}}=5.88 \times 10^{-17} T \frac{\sqrt{\psi_{\mathrm{H}_{2} \mathrm{O}} M_{\mathrm{H}_{2} \mathrm{O}}}}{\mu_{1} V_{i, \mathrm{~m}}^{0.6}} \text { in } \mathrm{m}^{2} \mathrm{~s}^{-1}
$$

$\psi_{\mathrm{H}_{2} \mathrm{O}}=2.26$ is an "association parameter" for the solvent water, ${ }^{84} \mu_{1}$ and $M_{\mathrm{H}_{2} \mathrm{O}}$ are the viscosity and molar mass of liquid water, and $V_{i, \mathrm{~m}}$ is the molal volume of species $i$ at normal boiling point. The $V_{i, \mathrm{~m}}$ can be estimated either by the method of Le $\mathrm{Bas}^{85}$ or, in the case of $\mathrm{HF}$, the method of Tyn and Calus, ${ }^{86}$ based on the value of the critical volume in Reid et al. ${ }^{84}$ The volume increments required in the Le Bas method are given by Satterfield. ${ }^{87}$

The weak polymer end groups degrade to form carboxylic acid end groups according to Reaction 8; their concentration, $c_{\text {wpe }}$, satisfies (in the CLs and membrane)

$$
\frac{\partial c_{\mathrm{wpe}}}{\partial t}=-q_{8}
$$

$-\mathrm{COOH}$ groups are produced by Reactions 8 and 9 . There is no net production or consumption of - $\mathrm{COOH}$ groups from Reaction 7 provided a $\mathrm{CF}_{2}$ group is available on the backbone structure for the unzipping to continue. Once the $\mathrm{CF}_{2}$ groups are exhausted, the $\mathrm{COOH}$ concentration decays to zero. Accordingly, the equation for the concentration of $-\mathrm{COOH}$ groups, $c_{\text {carb }}$, valid in both the CLs and the membrane, can be written as

$$
\frac{\partial c_{\mathrm{carb}}}{\partial t}=q_{8}+q_{9}-q_{7}+q_{7} H\left(-c_{\mathrm{CF}_{2}}^{\min }+c_{\mathrm{CF}_{2}}\right)
$$

where $H(\cdot)$ is the heaviside function. The last two terms on the right side ensure that Reaction 7 does not contribute to the mass balance, provided the backbone $\mathrm{CF}_{2}$ group concentration, $c_{\mathrm{CF}_{2}}$, is greater than the minimum value, $c_{\mathrm{CF}_{2}}^{\min }$. When the minimum value is reached,

Table IV. Sources and sinks for the dissolved reactants, dissolved water, and potential equations, Eq. 17, 24, and 28, respectively.

\begin{tabular}{lccc} 
& ACL & CCL \\
\hline$S_{\mathrm{O}_{2}}$ & $-q_{4}-q_{1}$ & $\frac{1}{4} q_{11}-q_{1}$ & 0 \\
$S_{\mathrm{H}_{2}}$ & $-q_{2}$ & 0 & 0 \\
$S_{\mathrm{N}_{2}}$ & 0 & $q_{1}-q_{6 \mathrm{a}}$ & 0 \\
$S_{\mathrm{H}_{2} \mathrm{O}_{2}}$ & $q_{5}-q_{6 \mathrm{a}}$ & $q_{6 \mathrm{a}}-q_{7}-q_{8}-q_{9}-q_{10}$ & 0 \\
$S_{\mathrm{OH}}$ & $q_{6 \mathrm{a}}-q_{7}-q_{8}-q_{9}-q_{10}$ & $q_{6 \mathrm{a}}-q_{7}-q_{8}-q_{9}-q_{10}$ & 0 \\
$S_{\mathrm{HO}_{2}}$ & $q_{4}-q_{5}$ & $2 q_{7}+q_{9}+q_{10}$ & $q_{9}-q_{10}$ \\
$S_{\mathrm{HF}}$ & $2 q_{7}+q_{9}+q_{10}$ & $F\left(q_{11}+2 q_{1}\right)$ & $-S_{e}+q_{10}$ \\
$S_{\mathrm{A}}$ & $q_{9}-q_{10}$ & $q_{9}-q_{10}$ & 0 \\
$S_{\mathrm{e}}$ & $F\left(q_{3}-2 q_{1}\right)$ & $k_{\mathrm{d} \leftrightarrow 1}\left(c_{\mathrm{H}_{2} \mathrm{O}}^{\mathrm{d}}-c_{\mathrm{H}_{2} \mathrm{O}, 1}^{*}\right)$
\end{tabular}




\begin{tabular}{|c|c|c|c|c|}
\hline Term & Membrane & ACL & CCL & GDL \\
\hline$Q_{\text {act }}$ & 0 & $a F \eta_{\mathrm{A}} q_{3}$ & $F \eta_{\mathrm{C}} q_{\mathrm{O}_{2}}$ & 0 \\
\hline$Q_{\text {rev }}$ & 0 & $-\Delta s_{\mathrm{A}} T \mathrm{a} q_{3}$ & $\Delta s_{\mathrm{C}} T q_{\mathrm{O}_{2}}$ & 0 \\
\hline$Q_{\text {ohm }}$ & $\sigma_{+}\left(\frac{\partial \phi_{+}}{\partial y}\right)^{2}$ & $\sum_{i=+,-} \epsilon_{j}^{3 / 2} \sigma_{j}\left(\frac{\partial \phi_{j}}{\partial y}\right)^{2}$ & $\sum_{j=+,-} \epsilon_{j}^{3 / 2} \sigma_{j}\left(\frac{\partial \phi_{j}}{\partial y}\right)^{2}$ & $\left(1-\epsilon_{\mathrm{G}}\right)^{3 / 2} \sigma_{-}\left(\frac{\partial \phi_{-}}{\partial y}\right)^{2}$ \\
\hline$Q_{\mathrm{pc}}$ & 0 & $-h_{\mathrm{g} \mid} S_{\mathrm{g} \leftrightarrow 1}$ & $-h_{\mathrm{gl}} S_{\mathrm{g} \leftrightarrow 1}$ & $-h_{\mathrm{g} \mid} S_{\mathrm{g} \leftrightarrow 1}$ \\
\hline
\end{tabular}

the last term approaches zero and the remaining carboxylic groups are allowed to decay. The concentration of backbone $\mathrm{CF}_{2}$ groups is determined by the rate of Reaction 7

$$
\frac{\partial c_{\mathrm{CF}_{2}}}{\partial t}=-q_{7}+q_{7} H\left(-c_{\mathrm{CF}_{2}}^{\min }+c_{\mathrm{CF}_{2}}\right)
$$

The concentration of side chains, $c_{\text {side }}$, is governed by

$$
\frac{\partial c_{\text {side }}}{\partial t}=-q_{9}
$$

The mass balance for water dissolved in the electrolyte and membrane, normalized with respect to $v, c_{\mathrm{H}_{2} \mathrm{O}}^{\mathrm{d}}$, is derived by considering mass transfer and transport by diffusion and electro-osmotic drag

$$
\begin{aligned}
& \frac{\partial}{\partial t}\left(\epsilon c_{\mathrm{H}_{2} \mathrm{O}}^{\mathrm{d}}\right)-\frac{\partial}{\partial y}\left(\epsilon^{3 / 2} D_{\mathrm{H}_{2} \mathrm{O}}^{\mathrm{d}} \frac{\partial c_{\mathrm{H}_{2} \mathrm{O}}^{\mathrm{d}}}{\partial y}+\frac{5 \lambda}{44 F \nu} \epsilon^{3 / 2} \sigma_{+} \frac{\partial \phi_{+}}{\partial y}\right) \\
& = \begin{cases}0 & \text { membrane }(\epsilon=1) \\
-S_{\mathrm{d} \leftrightarrow \mathrm{g}}-S_{\mathrm{d} \leftrightarrow 1} & \text { CLs }\left(\epsilon=\epsilon_{\mathrm{e}}\right)\end{cases}
\end{aligned}
$$

in which $D_{\mathrm{H}_{2} \mathrm{O}}^{\mathrm{d}}$ is the diffusion coefficient of dissolved water through Nafion $^{88}$

$$
D_{\mathrm{H}_{2} \mathrm{O}}^{\mathrm{d}}=4.17 \times 10^{-8} \lambda\left(1+161 \mathrm{e}^{-\lambda}\right) \exp (-2436 / T) \text { in } \mathrm{m}^{2} \mathrm{~s}^{-1}
$$

The source term $S_{\mathrm{d} \leftrightarrow \mathrm{g}}$ was previously defined, and $S_{\mathrm{d} \leftrightarrow l}$, given in Table IV, is the rate of water mass transfer between the liquid and dissolved phases. Both are discussed below.

The mass balance of liquid water can be written as follows ${ }^{74}$

$$
\frac{\rho_{1}}{M_{1}} \frac{\partial s}{\partial t}-\frac{\partial}{\partial y}\left(\frac{\epsilon \rho_{1}}{M_{1}} \frac{\kappa s^{3}}{\mu_{1}} \frac{\partial p}{\partial y}\right)=-S_{\mathrm{g} \leftrightarrow 1}+\nu S_{\mathrm{d} \leftrightarrow 1}+S_{\mathrm{H}_{2} \mathrm{O}}
$$

where $\epsilon=\epsilon_{\mathrm{G}}$ in the GDLs and $\epsilon=\epsilon_{\mathrm{p}}$ in the CLs. $M_{\mathrm{l}}, \mu_{\mathrm{l}}$, and $p$ are the molar mass, viscosity, and pressure of the liquid water, respectively. The source term $S_{\mathrm{H}_{2} \mathrm{O}}$ is defined in Table IV and is the rate of liquid-water production. By definition, $p=p_{\mathrm{g}}-p_{\text {cap }}$, where $p_{\text {cap }}$ is the capillary pressure, which yields

$$
\frac{\epsilon \rho_{1}}{M_{1}} \frac{\partial s}{\partial t}+\frac{\kappa \rho_{1}}{\mu_{1} M_{1}} \frac{\partial}{\partial y}\left[s^{3}\left(\frac{d p_{\text {cap }}}{d s} \frac{\partial s}{\partial y}-\frac{\partial p_{\mathrm{g}}}{\partial y}\right)\right]=-S_{\mathrm{g} \leftrightarrow 1}+\nu S_{\mathrm{d} \leftrightarrow 1}+S_{\mathrm{H}_{2} \mathrm{O}}
$$

The widely used Leverette function, $\mathcal{J}(s)$, is adopted for the form of the capillary pressure

$$
p_{\text {cap }}=\sigma^{\prime} \cos \theta_{\mathrm{G}} \sqrt{\frac{\epsilon_{\mathrm{G}}}{\mathrm{\kappa}_{\mathrm{G}}}} \mathcal{J}(1-s), \quad p_{\text {cap }}=\sigma^{\prime} \cos \theta_{\mathrm{C}} \sqrt{\frac{\epsilon_{\mathrm{p}}}{\mathrm{\kappa}_{\mathrm{C}}}} \mathcal{J}(s)
$$

in the gas diffusion and CLs, respectively. $\sigma^{\prime}$ is the surface tension, and $\theta_{\mathrm{C}}$ and $\theta_{\mathrm{G}}$ are the contact angles in the CLs and GDLs, respectively.
Conservation of charge.-Equations for the potentials in the electrolyte/membrane and carbon phases, $\phi_{+}$and $\phi_{-}$, respectively, can be expressed as (assuming electroneutrality and a pseudo steady state)

$$
\begin{gathered}
\frac{\partial}{\partial y}\left(\epsilon_{\mathrm{e}}^{3 / 2} \sigma_{+} \frac{\partial \phi_{+}}{\partial y}\right)+S_{\mathrm{e}}=\frac{\partial}{\partial y}\left(\epsilon_{\mathrm{supp}}^{3 / 2} \sigma_{-} \frac{\partial \phi_{-}}{\partial y}\right)-S_{\mathrm{s}}=0 \text { CLs } \\
\frac{\partial}{\partial y}\left(\sigma_{+} \frac{\partial \phi_{+}}{\partial y}\right)=0 \text { membrane } \\
\frac{\partial}{\partial y}\left[\left(1-\epsilon_{\mathrm{G}}\right)^{3 / 2} \sigma_{-} \frac{\partial \phi_{-}}{\partial y}\right]=0 \text { GDLs }
\end{gathered}
$$

where $\epsilon_{\text {supp }}$ is the volume fraction of carbon support, $\sigma_{+}$and $\sigma_{-}$are the protonic and electronic conductivity, respectively, used with Bruggeman corrections to obtain their effective values, and $F$ is Faraday's constant. The source terms $S_{\mathrm{s}}$ and $S_{\mathrm{e}}$ are defined in Table IV and represent the electron and proton sources, respectively. The protonic conductivity of Nafion is assumed to take the form developed by Springer et al. ${ }^{89}$

$$
\sigma_{+}=(0.514 \lambda-0.326) \exp (1286 / 303-1286 / T) \text { in } \mathrm{S} \mathrm{m}^{-1}
$$

Thermal-energy conservation.- The thermal-energy balance can be written as follows, assuming a single temperature for all phases

$$
\frac{\partial}{\partial t}\left(\widehat{\rho c_{\mathrm{p}}} T\right)+\frac{\partial}{\partial y}\left[\epsilon s \rho_{1} c_{1} v_{1} T+\epsilon(1-s) \rho_{\mathrm{g}} c_{\mathrm{g}} v_{\mathrm{g}} T-\hat{k} \frac{\partial T}{\partial y}\right]=\sum_{\mathrm{k}} Q_{\mathrm{k}}
$$

where $\rho_{\mathrm{l}}, \rho_{\mathrm{g}}$, and $\rho_{\mathrm{s}}$ are the densities of the liquid, gas, and solid phases, respectively; $c_{1}, c_{\mathrm{g}}$, and $c_{\mathrm{s}}$ are the specific heat capacities of the liquid, gas, and solid phases, respectively; and $\hat{k}$ and $\widehat{\rho c_{\mathrm{p}}}$ are, respectively, the thermal conductivity and heat capacity volumeaveraged over all phases. The heat-generation terms $Q_{\mathrm{k}}$ are defined in Table V. In these expressions, $-\Delta s_{\mathrm{C}}$ is the entropy associated with the ORR and $-\Delta s_{\mathrm{A}}$ is the entropy associated with the HOR (note that as a simplification we neglect the heats of reaction of the other anode reactions). $h_{\mathrm{gl}}$ is the liquid-gas enthalpy change for water.

The thermal conductivity and thermal capacitance of the gas diffusion and CLs are volume-averaged over the constituents; that is, the carbon support, platinum, membrane, gas phase, and liquid water. The gas-phase thermal conductivity and specific heat capacity are approximated by the values for air (Table VI).

Mass transfer of the water.- Condensation and evaporation are assumed to be driven by the deviation from thermodynamic equilibrium $x_{\mathrm{v}} p_{\mathrm{g}}-p_{\text {sat }}$, where $p_{\text {sat }}$ is the saturation pressure and the first term, in which $x_{\mathrm{v}}$ is the vapor mole fraction, is the partial pressure of the vapor 


\begin{tabular}{|c|c|c|}
\hline Symbol & Quantity & Size \\
\hline$k_{\mathrm{N}}$ & Nafion thermal conductivity at $65^{\circ} \mathrm{C}$ and $50 \% \mathrm{RH}^{118}$ & $0.18 \mathrm{~W} \mathrm{~m}^{-1} \mathrm{~K}^{-1}$ \\
\hline$k_{\text {Tor }}$ & Toray paper thermal conductivity/graphite 102 & $7.63 \mathrm{~W} \mathrm{~m}^{-1} \mathrm{~K}^{-1}$ \\
\hline$k_{1}$ & Liquid-water thermal conductivity at $60^{\circ} \mathrm{C}^{118}$ & $0.66 \mathrm{~W} \mathrm{~m}^{-1} \mathrm{~K}^{-1}$ \\
\hline$k_{\mathrm{g}}$ & Gas-phase thermal conductivity/air at $60^{\circ} \mathrm{C}$ & $0.0285 \mathrm{~W} \mathrm{~m}^{-1} \mathrm{~K}^{-1}$ \\
\hline$k_{\mathrm{Pt}}^{g}$ & Pt thermal conductivity at $60^{\circ} \mathrm{C}^{120}$ & $73 \mathrm{~W} \mathrm{~m}^{-1} \mathrm{~K}^{-1}$ \\
\hline$k_{\text {supp }}$ & Carbon-support thermal conductivity/graphite ${ }^{102}$ & $7.63 \mathrm{~W} \mathrm{~m}^{-1} \mathrm{~K}^{-1}$ \\
\hline$\rho_{1}$ & Liquid-water density at $60^{\circ} \mathrm{C}^{119}$ & $980 \mathrm{~kg} \mathrm{~m}^{-3}$ \\
\hline$\rho_{\text {Tor }}$ & Toray paper density: base material ${ }^{121}$ & $2045 \mathrm{~kg} \mathrm{~m}^{-3}$ \\
\hline$\rho_{\text {supp }}$ & Carbon-support density/graphite & $2045 \mathrm{~kg} \mathrm{~m}^{-3}$ \\
\hline$c_{\mathrm{p}, \mathrm{N}}$ & Nafion specific heat capacity & $4188 \mathrm{~J} \mathrm{~kg}^{-1} \mathrm{~K}^{-1}$ \\
\hline$c_{\mathrm{p}, \mathrm{T} \text {, }}$ & Toray paper specific heat capacity/graphite ${ }^{122}$ & $685 \mathrm{~J} \mathrm{~kg}^{-1} \mathrm{~K}^{-1}$ \\
\hline$c_{\mathrm{p} \text {, supp }}$ & Carbon-support specific heat capacity/graphite ${ }^{122}$ & $685 \mathrm{~J} \mathrm{~kg}^{-1} \mathrm{~K}^{-1}$ \\
\hline$c_{\mathrm{p}, 1}^{\mathrm{p}, \mathrm{l}}$ & Liquid-water specific heat capacity at $60^{\circ} \mathrm{C}$ & $4188 \mathrm{~J} \mathrm{~kg}^{-1} \mathrm{~K}^{-1}$ \\
\hline$c_{\mathrm{p}, \mathrm{g}}$ & Gas-phase specific heat capacity/air at $60^{\circ} \mathrm{C}$ & $1009 \mathrm{~J} \mathrm{~kg}^{-1} \mathrm{~K}^{-1}$ \\
\hline$-\Delta s_{C}$ & Entropy associated with ORR ${ }^{123}$ & $163.7 \mathrm{~J} \mathrm{~mol}^{-1} \mathrm{~K}^{-1}$ \\
\hline$-\Delta s_{\mathrm{A}}$ & Entropy associated with $\mathrm{HOR}^{123}$ & $0 \mathrm{~J} \mathrm{~mol}^{-1} \mathrm{~K}^{-1}$ \\
\hline
\end{tabular}

$$
k_{\mathrm{g} \leftrightarrow 1}= \begin{cases}k_{\text {cond }} \frac{\epsilon_{\mathrm{p}}(1-s) x_{\mathrm{v}}}{R T} & x_{\mathrm{v}} p_{\mathrm{g}}-p_{\text {sat }}>0 \text { (condensation) } \\ k_{\text {evap }} \frac{\epsilon_{\mathrm{p}} s \rho_{1}}{M_{1}} & x_{\mathrm{v}} p_{\mathrm{g}}-p_{\text {sat }}<0 \text { (evaporation) }\end{cases}
$$

$k_{\text {cond }}$ and $k_{\text {evap }}$ are the condensation and evaporation rate constants. Note that the condition $x_{\mathrm{v}} p_{\mathrm{g}}=p_{\text {sat }}$ is equivalent to $a_{\mathrm{w}}=1$, where $a_{\mathrm{w}}$ is the water activity or equilibrium RH, i.e., condensation occurs when the environment is fully saturated.

In a similar fashion, the vapor-dissolved phase-change term in Eq. 14 and 24 is driven by the deviation from concentration equilibrium between the vapor and dissolved water, $c_{\mathrm{H}_{2} \mathrm{O}}^{\mathrm{d}}-c_{\mathrm{H}_{2} \mathrm{O}}^{*}$, where $c_{\mathrm{H}_{2} \mathrm{O}}^{*}$ is the dissolved water concentration at equilibrium with water vapor, as given by Hinatsu et al. ${ }^{90}$

$$
\lambda^{*}=0.3+10.8 a_{\mathrm{w}}-16 a_{\mathrm{w}}^{2}+14.1 a_{\mathrm{w}}^{3}, \quad c_{\mathrm{H}_{2} \mathrm{O}}^{*}=\frac{\lambda^{*} u}{1+0.0126 \lambda^{*}}
$$

In these formulas, $a_{\mathrm{w}}=x_{\mathrm{v}} p_{\mathrm{g}} / p_{\text {sat }}$ is the water vapor activity. The mass-transfer coefficient $k_{\mathrm{d} \leftrightarrow \mathrm{g}}$ is approximated from the results in Ge et al. ${ }^{91}$

$$
k_{\mathrm{d} \leftrightarrow \mathrm{g}}= \begin{cases}k_{\text {ads,g }}(1-s) \lambda & c_{\mathrm{H}_{2} \mathrm{O}}^{\mathrm{d}}-c_{\mathrm{H}_{2} \mathrm{O}}^{*}<0 \text { (adsorption) } \\ k_{\text {des,g }}(1-s) \lambda & c_{\mathrm{H}_{2} \mathrm{O}}^{\mathrm{d}}-c_{\mathrm{H}_{2} \mathrm{O}}^{*}>0 \text { (desorption) }\end{cases}
$$

for the desorption and adsorption coefficients $k_{\text {des,g }}$ and $k_{\text {ads,g }}$, respectively.

The equilibrium membrane water content depends on its environment, with either Eq. 32 for contact with vapor or $\lambda=\lambda_{1}^{*}$ $=16.8$ for contact with liquid water. The liquid-equilibrated dissolved water concentration is $c_{\mathrm{H}_{2} \mathrm{O}, 1}^{*}=\lambda_{1}^{*} /\left(u+0.0126 \lambda_{1}^{*}\right)$. The discontinuity between the vapor-saturated and liquid values is known as Schroeder's paradox. The mass-transfer term $S_{\mathrm{d} \leftrightarrow 1}$ in Eq. 24 and 25 and Table IV, is decomposed into terms for absorption and desorption of liquid water to and from the electrolyte in the CL. When the liquid-equilibrated water-content value $c_{\mathrm{H}_{2} \mathrm{O}, 1}^{*}$ is reached or exceeded, desorption of water from the electrolyte takes place as liquid, the magnitude of which is driven by $c_{\mathrm{H}_{2} \mathrm{O}}^{\mathrm{d}}-c_{\mathrm{H}_{2} \mathrm{O}, 1}^{*}$. Adsorption occurs for $c_{\mathrm{H}_{2} \mathrm{O}}^{\mathrm{d}}<c_{\mathrm{H}_{2} \mathrm{O}, \mathrm{l}}^{*}$, provided $s>s_{*}$, where $s_{*}$ is the immobile saturation. Under these conditions, the term $k_{\mathrm{d} \leftrightarrow 1}$ in Table IV takes the form

$$
k_{\mathrm{d} \leftrightarrow 1}=k_{\mathrm{des}, 1} H\left(c_{\mathrm{H}_{2} \mathrm{O}}^{\mathrm{d}}-c_{\mathrm{H}_{2} \mathrm{O}, 1}^{*}\right)+k_{\mathrm{ads}, 1} H\left(s-s_{*}\right) H\left(-c_{\mathrm{H}_{2} \mathrm{O}}^{\mathrm{d}}+c_{\mathrm{H}_{2} \mathrm{O}, 1}^{*}\right)
$$

where $H(\cdot)$ is the Heaviside function and $k_{\mathrm{ads}, 1}$ and $k_{\mathrm{ads}, 1}$ are the coefficients of water desorption and absorption to and from the electrolyte, respectively. Their values are chosen large enough that $c_{\mathrm{H}_{2} \mathrm{O}}^{\mathrm{d}}$ does not overshoot $c_{\mathrm{H}_{2} \mathrm{O}, 1}^{*}$ significantly (in the absence of known values).

Kinetics.- Oxygen reduction.- The kinetics of the direct, fourelectron reduction of $\mathrm{O}_{2}$ to water (Reaction 11) are well-captured by the Butler-Volmer expression under charge-transfer control

$$
q_{11}=\frac{a j_{\mathrm{O}_{2}, \text { ref }}}{F c_{\mathrm{O}_{2}, \text { ref }}} \epsilon_{e} c_{\mathrm{O}_{2}}^{\mathrm{s}}\left[\exp \left(\frac{\alpha_{\mathrm{A}} F \eta_{\mathrm{C}}}{R T}\right)-\exp \left(-\frac{\alpha_{\mathrm{C}} F \eta_{\mathrm{C}}}{R T}\right)\right]
$$

where $j_{\mathrm{O}_{2} \text {,ref }}$ is the exchange current density, $\alpha_{\mathrm{A}}$ and $\alpha_{\mathrm{C}}$ are the anodic and cathodic transfer coefficients, respectively, $c_{\mathrm{O}_{2} \text {,ref }}$ is the reference $\mathrm{O}_{2}$ molar concentration, $a$ is the volumetric specific surface area of catalyst, and $\eta_{C}$ is the overpotential

$$
\eta_{\mathrm{C}}=\phi_{-}-\phi_{+}-E_{0}
$$

$E_{0}$ is the open-circuit potential (OCP). Reaction 11 is the predominant reaction for reduction of $\mathrm{O}_{2}$ to water on platinum. The reduction of $\mathrm{H}_{2} \mathrm{O}_{2}$ to water (see Fig. 2) is assumed to be negligible. An agglomerate model is used for the CCL. The quantity $c_{\mathrm{O}_{2}}^{\mathrm{s}}$ in Eq. 35 is the $\mathrm{O}_{2}$ concentration at the agglomerate surfaces. It is related to the bulk value, $c_{\mathrm{O}_{2}}$, by balancing the rate of reaction at the agglomerate surfaces with the molar flux of $\mathrm{O}_{2}$ through the electrolyte and water films, yielding ${ }^{75,76}$

$$
\begin{aligned}
q_{11}= & 4 a^{\prime} \frac{A^{\prime} D_{1} A D_{\mathrm{O}_{2}}^{\mathrm{d}}}{A^{\prime} D_{1} \delta_{\mathrm{e}}+A D_{\mathrm{O}_{2}}^{\mathrm{d}} \delta_{1}} \\
& \times c_{\mathrm{O}_{2}} \frac{\mathrm{e}^{\alpha_{\mathrm{A}} F \eta_{\mathrm{C}} / R T}-\mathrm{e}^{-\alpha_{\mathrm{C}} F \eta_{\mathrm{C}} / R T}}{\frac{A^{\prime} D_{1} A D_{\mathrm{O}_{2}}^{\mathrm{d}}}{A^{\prime} D_{1} \delta_{\mathrm{e}}+A D_{\mathrm{O}_{2}}^{\mathrm{d}} \delta_{1}}+a^{\prime}\left(\mathrm{e}^{\alpha_{\mathrm{A}} F \eta_{\mathrm{C}} / R T}-\mathrm{e}^{-\alpha_{\mathrm{C}} F \eta_{\mathrm{C}} / R T}\right)}
\end{aligned}
$$

where $a^{\prime}=a j_{\mathrm{O}_{2} \text {,ref }} \epsilon_{\mathrm{e}} /\left(4 F c_{\mathrm{O}_{2}, \text { ref }}\right), \delta_{\mathrm{e}}$ and $\delta_{1}$ are the electrolyte and 
liquid-water film thicknesses, respectively, $N$ is the number of agglomerates per unit volume, $A=4 \pi R_{\mathrm{a}}^{2} N$ is the specific surface area of agglomerates, where $R_{\mathrm{a}}$ is the agglomerate radius, $A^{\prime}=4 \pi\left(R_{\mathrm{a}}\right.$ $\left.+\delta_{\mathrm{e}}\right)^{2} N$, and $D_{1}$ is the diffusion coefficient of $\mathrm{O}_{2}$ through liquid water.

The volume of electrolyte attached to the surface of each agglomerate is $\epsilon_{\mathrm{e}}^{\mathrm{f}} / N$, which, by assumption, covers the entire surface of the agglomerate. The electrolyte film thickness without swelling, $\delta_{e}^{\prime}$, and the volume fraction of electrolyte films without swelling, $\epsilon_{\mathrm{e}, 0}^{\mathrm{f}}$, are related by

$$
\delta_{\mathrm{e}}^{\prime}=\left(R_{\mathrm{a}}^{3}+\frac{3 \epsilon_{\mathrm{e}, 0}^{\mathrm{f}}}{4 \pi N}\right)^{1 / 3}-R_{\mathrm{a}}
$$

The electrolyte swelling results in a volume change equal to $\left(\epsilon_{\mathrm{e}}^{\mathrm{f}}\right.$ $\left.-\epsilon_{\mathrm{e}, 0}^{\mathrm{f}}\right) / N$ per agglomerate, yielding an electrolyte film thickness of

$$
\delta_{\mathrm{e}}=\left[\left(R_{\mathrm{a}}+\delta_{\mathrm{e}}^{\prime}\right)^{3}+\frac{3\left(\epsilon_{\mathrm{e}}^{\mathrm{f}}-\epsilon_{\mathrm{e}, 0}^{\mathrm{f}}\right)}{4 \pi N}\right]^{1 / 3}-R_{\mathrm{a}}
$$

When the liquid-water saturation exceeds the immobile saturation, $s_{*}$, the water forms a contiguous phase and provides additional resistance to $\mathrm{O}_{2}$ transport. Given the hydrophilic nature of the electrolyte, it is assumed that the liquid water coats the entire surface of the agglomerates. Based on these assumptions, the water-layer thickness is

$$
\delta_{1}=\left[\left(R_{\mathrm{a}}+\delta_{\mathrm{e}}\right)^{3}+\frac{3 s \epsilon_{\mathrm{p}}}{4 \pi N}\right]^{1 / 3}-\left(R_{\mathrm{a}}+\delta_{\mathrm{e}}\right)
$$

and the total film thickness is given by $\delta=\delta_{\mathrm{e}}+\delta_{\mathrm{l}}$. The volumetric specific surface area of platinum is $a=a_{\mathrm{Pt}} m_{\mathrm{Pt}} / L$, where $a_{\mathrm{Pt}}$ is the mass specific platinum surface area, $m_{\mathrm{Pt}}$ is the platinum loading, and $L_{C}$ is the CL thickness. The number of agglomerates per unit volume is estimated from the agglomerate radius and the volumetric active specific surface area of catalyst: $N=a /\left(4 \pi R_{\mathrm{a}}^{2}\right)$.

$\mathrm{H}_{2}$ oxidation and $\mathrm{H}_{2} \mathrm{O}_{2}$ formation.- The rate of Reaction 1 in the cathode, $q_{1}$, is given by the Butler-Volmer expression

$$
q_{1}=a r_{1} c_{\mathrm{O}_{2}}^{\mathrm{s}} c_{\mathrm{H}^{+}}^{2} \exp \left(\frac{-2 \alpha_{1} F \eta_{1}}{R T}\right)
$$

in which $\alpha_{1}$ is the transfer coefficient, $r_{1}$ is the forward reaction constant, and the overpotential $\eta_{1}$ is defined as

$$
\eta_{1}=\phi_{-}-\phi_{+}-E_{1}
$$

$E_{1}=0.695 \mathrm{~V}$ is the equilibrium potential for Reaction $1 \mathrm{vs}$ SHEs. ${ }^{29,39,51}$ In the anode, $\mathrm{H}_{2}$ is adsorbed and electro-oxidated on the platinum catalyst according to the Tafel-Volmer Reactions 2 and 3 . The surface coverage of $\mathrm{H}, \theta_{\mathrm{H}}$, is given by the following ordinary differential equation

$$
\tau \frac{d \theta_{\mathrm{H}}}{d t}=2 \mathrm{q}_{2}-\mathrm{q}_{3}
$$

where $\tau$ is the molar area density of catalyst sites and $q_{2}$ and $q_{3}$ are the rates of Reactions 2 and 3, respectively. In deriving Eq. 43 it was assumed that coverage does not exceed a monolayer. The rates of Reactions 2-5 are given by

$$
\begin{gathered}
q_{2}=r_{2 \mathrm{f}} c_{\mathrm{H}_{2}}^{\mathrm{d}} \theta_{\mathrm{Pt}}^{2}-r_{2 \mathrm{~b}} \theta_{\mathrm{H}}^{2} \\
q_{3}=r_{3} \theta_{\mathrm{H}} \sinh \left(F \eta_{\mathrm{A}} / 2 R T\right) \\
q_{4}=r_{4} c_{\mathrm{H}} c_{\mathrm{O}_{2}}^{\mathrm{d}} \\
q_{5}=r_{5} c_{\mathrm{HO}_{2}} c_{\mathrm{H}}
\end{gathered}
$$

respectively. In these expressions, $r_{i}$ are the forward rate constants for Reactions 1-7. A Butler-Volmer expression is used for Reaction 3 and the rate of Reaction 2 is based on Frumkin kinetics. The surface coverage of free platinum sites, $\theta_{\mathrm{Pt}}$, is given by

$$
\theta_{\mathrm{Pt}}=1-\theta_{\mathrm{H}}
$$

and the overpotential for Reaction $3, \eta_{\mathrm{A}}$, is defined as

$$
\eta_{\mathrm{A}}=\phi_{-}-\phi_{+}
$$

In the model, $\mathrm{H}$. radicals participate only in Reactions 4 and 5 so there is no loss of generality in assuming that they are consumed within the ACL and do not leave the electrolyte phase. The concentration of $\mathrm{H}$ adatoms is calculated from the $\mathrm{H}$ surface coverage and volumetric concentration of free platinum sites as follows

$$
c_{\mathrm{H}}=a \tau \theta_{\mathrm{H}}
$$

Radical formation and attack on the membrane.- The rates of Reactions 6-10 are given by

$$
\begin{gathered}
q_{6 \mathrm{a}}=r_{6 \mathrm{a}} c_{\mathrm{M}^{2}+c_{\mathrm{H}_{2} \mathrm{O}_{2}}^{\mathrm{d}}} \\
q_{7}=r_{7} c_{\mathrm{carb}}\left(c_{\mathrm{OH}}^{\mathrm{d}}\right)^{2} \\
q_{8}=r_{8} c_{\mathrm{wpe}} c_{\mathrm{OH}}^{\mathrm{d}} \\
q_{9}=r_{9} c_{\mathrm{side}} c_{\mathrm{OH}}^{\mathrm{d}} \\
q_{10}=r_{10} c_{\mathrm{A}}\left(c_{\mathrm{OH}}^{\mathrm{d}}\right)^{2}
\end{gathered}
$$

where $r_{i}$ is the rate constant for Reactions 1-7.

Initial and boundary conditions.- At the interfaces between the membrane and CLs, $y=y_{2}$ and $y=y_{3}$ in Fig. 4, the gas-phase and liquid-water fluxes are taken to be zero; that is, the gas species and liquid water do not penetrate the membrane. Similarly, the fluxes of protons and dissolved species at the CL/GDL interfaces, $y=y_{1}$ and $y=y_{4}$, are taken to be negligibly small

$$
y=y_{1}, y_{4}: \quad D_{i}^{\mathrm{d}} \frac{\partial c_{i}^{\mathrm{d}}}{\partial y}=\sigma_{+} \frac{\partial \phi_{+}}{\partial y}=D_{\mathrm{H}_{2} \mathrm{O}}^{\mathrm{d}} \frac{\partial c_{\mathrm{H}_{2} \mathrm{O}}^{\mathrm{d}}}{\partial y}+\frac{5 \lambda \sigma_{+}}{44 F v} \frac{\partial \phi_{+}}{\partial y}=0
$$

$$
y=y_{2}, y_{3}: \quad \epsilon_{\mathrm{p}}(1-s) D_{i} \frac{\partial c_{i}}{\partial y}-v_{\mathrm{g}} c_{i}=\frac{\partial s}{\partial y}=0
$$

At the interfaces between the channels and GDLs the mole fractions of $\mathrm{H}_{2}, \mathrm{O}_{2}, \mathrm{~N}_{2}$, and $\mathrm{H}_{2} \mathrm{O}$ are prescribed (or calculated from the other conditions)

$$
x_{i}=\left\{\begin{array}{ll}
\bar{x}_{i, C} & y=y_{0} \\
\bar{x}_{i, \mathrm{~A}} & y=y_{5}
\end{array}, \quad i=\mathrm{H}_{2}, \mathrm{O}_{2}, \mathrm{~N}_{2}, \mathrm{H}_{2} \mathrm{O}\right.
$$

Likewise, temperature, water activity, and pressure are prescribed according to average values in the channels

$$
T\left(y_{0}\right)=T_{\mathrm{C}} \quad p_{\mathrm{g}}\left(y_{0}\right)=p_{\mathrm{g}, \mathrm{C}} \quad p_{\mathrm{g}}\left(y_{5}\right)=p_{\mathrm{g}, \mathrm{A}}, \quad a_{\mathrm{w}}\left(y_{0}\right)=a_{\mathrm{w}, \mathrm{C}}
$$

and similarly at the anode, with subscript $C$ replaced with $A$. The concentrations of water vapor in the cathode and anode channels, $\bar{c}_{\mathrm{v}, \mathrm{C}}$ and $\bar{c}_{\mathrm{v}, \mathrm{A}}$, respectively, are calculated from the water activities given in Eq. 56. The saturation pressure is a function of temperature and is given by the following formula (bars) ${ }^{89}$

$$
\begin{aligned}
\log _{10} p_{\text {sat }}= & -2.1794+0.02953(T-273.15)-9.1837 \\
& \times 10^{-5}(T-273.15)^{2}+1.4454 \times 10^{-7}(T-273.15)^{3}
\end{aligned}
$$

From the above relationships, the vapor concentrations in the channels can be calculated 


\begin{tabular}{|c|c|c|}
\hline Symbol & Quantity & Size \\
\hline$T_{\mathrm{C}}$ & Cathode channel temperature & $60^{\circ} \mathrm{C}$ \\
\hline$T_{\mathrm{A}}$ & Anode channel temperature & $60^{\circ} \mathrm{C}$ \\
\hline$a_{\mathrm{w}, \mathrm{C}}$ & Cathode channel water activity & 0.9 \\
\hline$a_{\mathrm{w}, \mathrm{A}}$ & Anode channel water activity & 0.9 \\
\hline $\bar{x}_{\mathrm{O}_{2}, \mathrm{C}}$ & Oxygen mole fraction in cathode channel ${ }^{\mathrm{a}}$ & 0.21 \\
\hline $\bar{x}_{\mathrm{H}_{2}, \mathrm{~A}}$ & Hydrogen mole fraction in anode channel ${ }^{\mathrm{a}}$ & 0.2 \\
\hline $\bar{x}_{\mathrm{N}_{2}, \mathrm{C}}$ & Nitrogen mole fraction in cathode channel ${ }^{\mathrm{a}}$ & 0.79 \\
\hline $\bar{x}_{\mathrm{N}_{2}, \mathrm{~A}}$ & Nitrogen mole fraction in anode channel ${ }^{\mathrm{a}}$ & 0.8 \\
\hline$p_{\mathrm{g}, \mathrm{C}}$ & Gas pressure in the cathode channel & $300 \mathrm{kPa}$ \\
\hline$p_{\mathrm{g}, \mathrm{A}}$ & Gas pressure in the anode channel & $300 \mathrm{kPa}$ \\
\hline $\bar{c}_{\mathrm{H}_{2} \mathrm{O}, \mathrm{C}}$ & Vapor concentration in cathode channel & $6.38 \mathrm{~mol} \mathrm{~m}^{-3}$ \\
\hline $\bar{c}_{\mathrm{H}_{2} \mathrm{O}, \mathrm{A}}$ & Vapor concentration in the anode channel & $6.38 \mathrm{~mol} \mathrm{~m}^{-3}$ \\
\hline$\left[\mathrm{Fe}^{2+}\right]_{0}$ & $\mathrm{Fe}^{2+}$ concentration in the membrane/electrolyte & $20 \mathrm{ppm}$ \\
\hline$c_{\mathrm{carb}, 0}$ & Initial carboxylic acid concentration & $1170 \mathrm{~mol} \mathrm{~m}^{-3}$ \\
\hline$c_{\mathrm{wpe}, 0}$ & Initial weak polymer end group concentration & $1170 \mathrm{~mol} \mathrm{~m}^{-3}$ \\
\hline$c_{\text {side }, 0}$ & Initial side-chain concentration & $1800 \mathrm{~mol} \mathrm{~m}^{-3}$ \\
\hline$c_{\mathrm{CF}_{2}, 0}$ & Initial $\mathrm{CF}_{2}$ group concentration & $2.106 \times 10^{4} \mathrm{~mol} \mathrm{~m}^{-3}$ \\
\hline$E_{\text {cell }}$ & Applied cell voltage & $E_{0}$ \\
\hline
\end{tabular}

$$
\bar{c}_{\mathrm{v}, \mathrm{C}}=\frac{a_{\mathrm{w}, \mathrm{C}} p_{\mathrm{sat}, \mathrm{C}}}{R T_{\mathrm{C}}} \quad \text { or } \quad \bar{x}_{\mathrm{v}, \mathrm{C}}=\frac{a_{\mathrm{w}, \mathrm{C}} p_{\mathrm{sat}, \mathrm{C}}}{p_{\mathrm{g}, \mathrm{C}}}
$$

where $p_{\text {sat }, \mathrm{C}}$ is the cathode-channel saturation pressure (expressed in $\mathrm{Pa})$. A similar calculation applies on the anode side, where the channel saturation pressure is $p_{\text {sat,A. }}$.

For operation in the potentiostatic mode, the cell voltage, $E_{\text {cell }}$, is prescribed at the cathode channel/GDL interface. At the anode channel/GDL interface, the electronic potential is set to zero

$$
\phi_{-}\left(y_{0}\right)=E_{\text {cell }}, \quad \phi_{-}\left(y_{5}\right)=0
$$

At the interfaces between the gas channels and the GDL, it is assumed that the flow rate is high enough to maintain zero saturation and zero gas concentrations of $\cdot \mathrm{OH}, \mathrm{H}_{2} \mathrm{O}_{2}$, and $\mathrm{HF}$

$$
y=y_{0}, y_{5}: \quad s=c_{\mathrm{HF}}=c_{\mathrm{H}_{2} \mathrm{O}_{2}}=c_{\mathrm{OH}}=0
$$

The initial conditions for the pressures, temperatures, and vapor concentrations are consistent with the conditions in the channels. In the cathode, the electronic potential is given by the OCP and is uniformly equal to zero on the anode. The protonic potential is zero in all regions. The water content of the membrane/electrolyte is given by equilibrium with the vapor in the channels, and the liquidwater saturation is uniformly zero. Compositions of $20 \%$ hydrogen in $80 \%$ nitrogen at the anode and air at the cathode are used, which are representative of some poisoning and degradation tests. ${ }^{92}$ Values as low as $10 \%$ hydrogen have been used by Ohma et al. ${ }^{93}$ Importantly, the precise value does not qualitatively affect any of the results presented below.

The initial surface coverage of $\mathrm{H}$ (in the anode) is taken to be zero. The initial concentrations of $-\mathrm{COOH}$ groups, weak polymer end groups, $\mathrm{CF}_{2}$ groups, and side chains are based on their values for Nafion and are given in Table VII. The side-chain concentration coincides with the fixed charge site concentration, $v$ $=1800 \mathrm{~mol} \mathrm{~m}^{-3}$. The structure and properties of Nafion were extensively reviewed by Mauritz and Moore $;{ }^{4}$ using Fig. 1 as a guide, the relationship between the equivalent weight, $E W$, and the weight, $m$, is $E W=100 m+446$, assuming that $n=1$. This formula yields an approximate value of $13 \mathrm{CF}_{2}$ groups per side chain and a total concentration of approximately $13 v=2.34 \times 10^{4} \mathrm{~mol} \mathrm{~m}^{-3}$. The initial $-\mathrm{COOH}$ and weak polymer end-group concentrations depend on several factors related mainly to the manufacturing process. They are both set at $5 \%$ of the $\mathrm{CF}_{2}$ group concentration (which reduces the initial $\mathrm{CF}_{2}$ concentration by $10 \%$ ) in all simulations. Altering these values does not qualitatively affect the results presented below.

Parameters and numerical details.- In Tables I, III, and VI-XI, the default set of parameter values are listed. The values are taken from the literature, with references provided, or are either estimated or assumed. The component thicknesses are within the normal range of values reported. The membrane/electrolyte property values are based on Nafion, subject to the availability of data. The GDL properties are based on Toray TGP-H-060 carbon-fiber paper.

The proton concentration is related to the equivalent weight, $E W$, and the density, $\rho_{N}$, of Nafion as follows

$$
c_{\mathrm{H}^{+}}=\frac{\rho_{N}}{E W}
$$

in mol m $\mathrm{m}^{-3}$. The density of Nafion is related to its water content as follows 29

$$
\rho_{N}=\frac{1.98+0.0324 \lambda}{1+0.0648 \lambda} \times 10^{-3}
$$

in $\mathrm{kg} \mathrm{m}^{-3}$. Expressions 60 and 61 relate the rate of $\mathrm{H}_{2} \mathrm{O}_{2}$ formation from Reaction 1 to the channel water activities, which largely determine the membrane water content and the $\mathrm{pH}$ of the electrolyte, which is a function of the proton concentration. The rate constant $r_{1}$ was estimated by Sethuraman et al. ${ }^{29}$ based on the form

$$
r_{i}=r_{i}^{0} \exp \left(-\frac{E_{\text {act }, i}}{R T}\right)
$$

with $i=1$, where $E_{\text {act, } 1}$ is the activation energy characterizing the dependence of $r_{1}$ on temperature. Values for $r_{1}^{0}$ and $E_{\text {act, } 1}$ are given in Table X; the value of $r_{1}^{0}$ obtained by Sethuraman and co-workers was converted to the equivalent volumetric value using the active surface area of platinum.

The rate constants for the Tafel and Volmer reactions, Reactions 2 and 3 , respectively, are given by Baschuk and $\mathrm{Li}^{95}$ and the rate constants for the peroxide and radical producing reactions, Reactions 4, 5, and 6a, have been determined by Christensen and co-workers ${ }^{58,96}$ based on Eq. 62 . The values of $r_{i}^{0}$ and $E_{\text {act }, i}$ are given in Table X. Note that ferrous iron, $\mathrm{Fe}^{2+}$, is used as the representative 


\begin{tabular}{|c|c|c|}
\hline Symbol & Quantity & Size \\
\hline$L_{\mathrm{C}}$ & CL thickness ${ }^{\mathrm{a}}$ & $25 \mu \mathrm{m}$ \\
\hline$L_{\mathrm{M}}$ & Membrane thickness ${ }^{\mathrm{a}}$ & $50 \mu \mathrm{m}$ \\
\hline$L_{\mathrm{G}}$ & GDL thickness $^{\mathrm{a}}$ & $200 \mu \mathrm{m}$ \\
\hline$\epsilon_{\mathrm{e}}$ & Total initial electrolyte volume fraction: $\mathrm{CLs}^{\mathrm{a}}$ & 0.35 \\
\hline$\epsilon_{\mathrm{p}}$ & Volume fraction of primary pores without swelling ${ }^{101}$ & 0.15 \\
\hline$\epsilon_{\mathrm{sp}}$ & Volume fraction of small pores in CLs ${ }^{\mathrm{a}}$ & 0.07 \\
\hline$\epsilon_{\text {supp }}$ & Volume fraction of carbon support ${ }^{\mathrm{a}}$ & 0.35 \\
\hline$\epsilon_{\mathrm{Pt}}$ & Volume fraction of $\mathrm{Pt}$ in $\mathrm{CLs}^{102}$ & 0.08 \\
\hline$\epsilon_{\mathrm{G}}$ & Porosity of the GDL ${ }^{103}$ & 0.78 \\
\hline$R_{\mathrm{a}}$ & Agglomerate radius ${ }^{104}$ & $0.5 \mu \mathrm{m}$ \\
\hline$\delta^{\prime}$ & Ionomer film thickness without swelling ${ }^{\mathrm{a}}$ & $0.1 \mu \mathrm{m}$ \\
\hline$a_{\mathrm{Pt}}$ & Specific surface area of platinum ${ }^{105}$ & $1000 \mathrm{~cm}^{2}(\mathrm{mg} \mathrm{Pt})^{-1}$ \\
\hline$m_{\mathrm{Pt}}$ & Platinum loading ${ }^{\mathrm{a}}$ & $0.4(\mathrm{mg} \mathrm{Pt}) \mathrm{cm}^{-2}$ \\
\hline$\theta_{\mathrm{C}}$ & CL contact angle ${ }^{106}$ & $90^{\circ}$ \\
\hline$d_{\mathrm{G}}$ & GDL pore diameter ${ }^{103}$ & $23 \mu \mathrm{m}$ \\
\hline$d_{\mathrm{C}}$ & CL pore diameter ${ }^{103}$ & $2 \mu \mathrm{m}$ \\
\hline
\end{tabular}

metal ion. The initial concentration of $\mathrm{Fe}^{2+},\left[\mathrm{Fe}^{2+}\right]_{0}$, is given in ppm of the membrane/electrolyte in Table VII. This value is converted to the equivalent in mol per $\mathrm{m}^{3}$ of Nafion as follows

$$
c_{\mathrm{Fe}^{2+}}^{0}=\frac{\left[\mathrm{Fe}^{2+}\right]_{0} \rho_{\mathrm{N}}}{M_{\mathrm{Fe}}}
$$

which is valid in the CLs and membrane. $M_{\mathrm{Fe}}$ is the molar mass of Fe.

\begin{tabular}{|c|c|c|}
\hline Symbol & Quantity & Size \\
\hline$j_{\mathrm{O}_{2} \text { ref }}$ & Cathode exchange current density ${ }^{107}$ & $10^{-2} \mathrm{~A} \mathrm{~m}^{-2}$ \\
\hline$c_{\mathrm{O}_{2} \text {,ref }}$ & Reference $\mathrm{O}_{2}$ concentration & $0.05 \mathrm{~mol} \mathrm{~m}^{-3}$ \\
\hline$\alpha_{C}^{2, \text { ref }}$ & Cathodic transfer coefficient & 0.55 \\
\hline$\alpha_{A}$ & Anodic transfer coefficient & 0.45 \\
\hline$\sigma_{-}$ & Through-plane electronic conductivity ${ }^{103}$ & $1250 \mathrm{~S} \mathrm{~m}^{-1}$ \\
\hline$\tau$ & Molar area density of platinum sites ${ }^{108}$ & $0.01042 \mathrm{~mol} \mathrm{~m}^{-2}$ \\
\hline
\end{tabular}

The four remaining rate constants related to the degradation model are unknown: $-\mathrm{COOH}$ formation $\left(r_{7}\right)$, end-group unzipping $\left(r_{8}\right)$, side-chain cleavage $\left(r_{9}\right)$, and molecule A decomposition $\left(r_{10}\right)$. The values of these constants were adjusted to provide a fit to experimentally obtained rates of $\mathrm{HF}$ and $\mathrm{H}_{2} \mathrm{O}_{2}$ formation. It is emphasized that the main objectives of this study can be achieved by qualitative comparisons of the numerical simulations to experimental data. Nevertheless, to gain some understanding of the behavior of the system with respect to variations in the underlying rate constants, parametric studies in the values of $r_{7}-r_{9}$ were performed.

The initial-boundary value problem was solved in the software package COMSOL Multiphysics on a uniform, one-dimensional grid (typically 512 points) using quartic Lagrange polynomials as trial and test functions in the finite-element methodology. For the base-case parameters shown in Tables I, III, and VI-XI and using 256 grid points, simulation of $308 \mathrm{~h}$ of operation, by which time degradation was complete, took $563 \mathrm{~s}$ on an Athlon 64 X2 Dualcore $2.4 \mathrm{GHz}$ processor with $5 \mathrm{~Gb}$ of RAM. The equivalent calculation took $752 \mathrm{~s}$ using 512 grid points. For the base-case parameters and side-chain cleavage in included reactions (Reactions 9 and

Table X. Rate constants used in the calculations.

\begin{tabular}{|c|c|c|}
\hline Symbol & Quantity & Size \\
\hline$r_{1}^{0}$ & Forward rate constant for Reaction $1^{29}$ & $23.1 \mathrm{~mol} \mathrm{~m}^{-2} \mathrm{~s}^{-1}$ \\
\hline$r_{2 f}^{0}$ & Forward rate constant for Reaction $2^{95}$ & $3 \mathrm{~m} \mathrm{~s}^{-1}$ \\
\hline$r_{2 \mathrm{~b}}^{0} / r_{2 \mathrm{f}}$ & Backward rate constant for Reaction $2^{95}$ & $4.18 \times 10^{11} \mathrm{~mol} \mathrm{~m}^{-3}$ \\
\hline$r_{3}^{0}$ & Rate constant for Reaction $3^{95}$ & $23.1 \mathrm{~mol} \mathrm{~m}^{-2} \mathrm{~s}^{-1}$ \\
\hline$r_{4}^{0}$ & Forward rate constant for Reaction $4^{58}$ & $2.04 \times 10^{2} \mathrm{~m}^{3} \mathrm{~mol}^{-1} \mathrm{~s}^{-1}$ \\
\hline$r_{5}^{0}$ & Forward rate constant for Reaction $5^{58}$ & \\
\hline$r_{6 \mathrm{a}}^{0}$ & Rate constant for Reaction $6 a^{96}$ & $5.2 \times 10^{-5} \mathrm{~m}^{3} \mathrm{~mol}^{-1} \mathrm{~s}^{-1}$ \\
\hline$r_{7}$ & Rate constant for Reaction 7 & $1 \mathrm{~mol}^{-2} \mathrm{~m}^{6} \mathrm{~s}^{-1}$ \\
\hline$r_{8}$ & Rate constant for Reaction 8 & $1 \times 10^{3} \mathrm{~mol}^{-1} \mathrm{~m}^{3} \mathrm{~s}^{-1}$ \\
\hline$r_{9}$ & Rate constant for Reaction 9 & $0 \mathrm{~mol}^{-1} \mathrm{~m}^{3} \mathrm{~s}^{-1}$ \\
\hline$r_{10}$ & Rate constant for Reaction 10 & $0 \mathrm{~mol}^{-2} \mathrm{~m}^{6} \mathrm{~s}^{-1}$ \\
\hline$E_{\text {act }, 1}$ & Activation energy for Reaction $1^{29}$ & $13.9 \mathrm{~kJ} \mathrm{~mol}^{-1}$ \\
\hline$E_{\text {act, } 2 \mathrm{f}}$ & Activation energy for forward part of Reaction $2^{95}$ & $10.4 \mathrm{~kJ} \mathrm{~mol}^{-1}$ \\
\hline$E_{\text {act }, 2 \mathrm{~b}}$ & Activation energy for backward part of Reaction $2^{95}$ & $87.9 \mathrm{~kJ} \mathrm{~mol}^{-1}$ \\
\hline$E_{\mathrm{act}, 3}$ & Activation energy for Reaction $3^{95}$ & $16.7 \mathrm{~kJ} \mathrm{~mol}^{-1}$ \\
\hline$E_{\text {act, } 4}$ & Activation energy for Reaction $4^{96}$ & $10.3 \mathrm{~kJ} \mathrm{~mol}^{-1}$ \\
\hline$E_{\text {act, } 5}^{a c t,}$ & Activation energy for Reaction $5^{96}$ & $14.2 \mathrm{~kJ} \mathrm{~mol}^{-1}$ \\
\hline$E_{\text {act,6a }}$ & Activation energy for Reaction $6 a^{96}$ & $42 \mathrm{~kJ} \mathrm{~mol}^{-1}$ \\
\hline
\end{tabular}




\section{Table XI. Liquid-phase diffusion parameters and convection parameters.}

\begin{tabular}{lll} 
Symbol & \multicolumn{1}{c}{ Quantity } & Size \\
\hline$V_{\mathrm{H}_{2}}^{\mathrm{d}}$ & Molal volume of $\mathrm{H}_{2}$ at n.b.p. ${ }^{\mathrm{a}}$ & $1.43 \times 10^{-5} \mathrm{~m}^{3} \mathrm{~mol}^{-1}$ \\
$V_{\mathrm{O}_{2}}$ & Molal volume of $\mathrm{O}_{2}$ at n.b.p. & $2.56 \times 10^{-5} \mathrm{~m}^{3} \mathrm{~mol}^{-1}$ \\
$V_{\mathrm{H}_{2} \mathrm{O}_{2}}$ & Molal volume of $\mathrm{H}_{2} \mathrm{O}_{2}$ n.b.p. & $22.2 \mathrm{~m}^{3} \mathrm{~mol}^{-1}$ \\
$V_{\mathrm{HF}}$ & Molal volume of $\mathrm{HF}$ at n.b.p. & $2.41 \times 10^{-5} \mathrm{~m}^{3} \mathrm{~mol}^{-1}$ \\
$V_{\mathrm{OH}}$ & Molal volume of OH at n.b.p. & $11.1 \mathrm{~m}^{3} \mathrm{~mol}^{-1}$ \\
$V_{\mathrm{A}}$ & Molal volume of molecule A at n.b.p. & $221.0 \mathrm{~m}^{3} \mathrm{~mol}^{-1}$ \\
$\mu_{1}$ & Liquid-water viscosity at $60^{\circ} \mathrm{C}^{111}$ & $4.67 \times 10^{-4} \mathrm{~Pa} \mathrm{~s}^{\circ}$ \\
$\mu_{1}$ & Liquid-water viscosity at $100^{\circ} \mathrm{C}^{111}$ & $2.82 \times 10^{-4} \mathrm{~Pa} \mathrm{~s}^{-}$ \\
$\sigma^{\prime}$ & Liquid-water surface tension (air contact) at $60^{\circ} \mathrm{C}$ & $0.066 \mathrm{~N} \mathrm{~m}^{-1}$
\end{tabular}

${ }^{\mathrm{a}}$ n.b.p. $=$ normal boiling point

${ }^{\mathrm{b}}$ Le Bas method. ${ }^{85,87}$

10 with $r_{9}=r_{10}=1 \mathrm{~mol}^{-1} \mathrm{~m}^{3} \mathrm{~s}^{-1}$ ), the calculation took $1033 \mathrm{~s}$ to simulate $308 \mathrm{~h}$ using 256 grid points. It is clear from these statistics above that even with a fine grid and a high-order basis, the simulation times are short; parametric studies of real-time degradation (over several thousand hours) can be performed within several hours. Although in two and three dimensions the calculation times would increase significantly, they would still be much shorter than the typical timescales for long-life or accelerated experiment.

\section{Results and Discussion}

Effects of oxygen concentration at the OCV.- Figure 5 shows the simulation results for the base case parameter values in Tables I, III, and VI-XI, with channel temperatures of $60^{\circ} \mathrm{C}$, channel water activities of 0.9 (90\% equilibrium RH), and operation at the opencircuit voltage $(\mathrm{OCV})$. Figure 5a demonstrates the evolution of the $-\mathrm{COOH}$ group concentration from the interface between the CCL and GDL at $y=0.2 \mathrm{~mm}$ to the interface between the ACL and GDL at $y=0.3 \mathrm{~mm}$ at intervals of $28 \mathrm{~h}$. The weak end groups are rapidly depleted (within $112 \mathrm{~h}$ ), giving rise to an increase in the $-\mathrm{COOH}$ group concentration, from the initial uniform value of $2000 \mathrm{~mol} \mathrm{~m}^{-3}$ to a uniform value of $2340 \mathrm{~mol} \mathrm{~m}^{-3}$. A value of $r_{8}=1$ $\times 10^{3} \mathrm{~mol}^{-1} \mathrm{~m}^{3} \mathrm{~s}^{-1}$ was selected to ensure that the end groups were depleted rapidly, as expected. ${ }^{27}$ The $-\mathrm{COOH}$ groups react with hydroxyl radicals according to Reaction 7, with a concentration that remains steady provided $\mathrm{CF}_{2}$ groups exist on the backbone to continue the unzipping. When the $\mathrm{CF}_{2}$ groups are exhausted, the $-\mathrm{COOH}$ concentration decays to zero, as seen in Fig. 5a. Also evident from Fig. 5a, d, and $\mathrm{f}$ is that degradation proceeds in a wavelike manner, with the wave advancing toward a region of predominantly nondegraded membrane (on the cathode side), which is separated from a region of complete degradation to the rear of the wave. The implications of this behavior are discussed later.

A faster rate of degradation in the anode, evident in Fig. 5, is consistent with experimentally measured FERs using Nafion and similar membranes. ${ }^{23,36,38,97}$ The cause of the relatively low degradation rate in the cathode is the slow rate of $\mathrm{H}_{2} \mathrm{O}_{2}$ production via Reaction 1, which, in turn, is a result of a high positive overpotential; ${ }^{60}$ at the $\mathrm{OCV}$, the electronic and ionic potentials satisfy $\phi_{-} \approx 1.23$ and $\phi_{+} \approx 0$, respectively, yielding an overpotential of approximately

$$
\eta_{1}=\phi_{-}-\phi_{+}-\approx 1.23-0.695=0.535 \mathrm{~V}
$$

in Eq. 41. The rate of Reaction 1 is, therefore, exponentially small. The profiles of $\mathrm{H}_{2} \mathrm{O}_{2}$ and $\cdot \mathrm{OH}$ in Fig. 5c and d, respectively, show that the concentrations of these species are an order of magnitude higher in the vicinity of the ACL, as is the rate of $\cdot \mathrm{OH}$ production in Fig. 5e. Preferential degradation in the anode follows as a result. Diffusive transport of $\mathrm{H}_{2} \mathrm{O}_{2}$ from the anode to the cathode through the membrane would clearly occur as a result of the large concentration gradient in Fig. 5c. Without this diffusive transport, the $\mathrm{H}_{2} \mathrm{O}_{2}$ and, therefore, $\cdot \mathrm{OH}$ concentration in the cathode would be lower.
Toward the end of the degradation process ( $t=196 \mathrm{~h}$ and beyond), as the radicals continue to be produced but are no longer consumed to the rear of the wave in Fig. 5a, degradation in the cathode accelerates as a consequence of diffusive transport of the unreacted $\cdot \mathrm{OH}$ from the anode to cathode sides.

The evolution of the rate of HF production, $2 q_{7}$, is shown in Fig. 5f. Consistent with the profiles in Fig. 5a-e the production rate is faster in the anode up to $t=140 \mathrm{~h}$. Thereafter, the profiles exhibit peaks that follow the wave front in Fig. 5a (separating the region of completely depleted $-\mathrm{COOH}$ from the region of partially depleted $-\mathrm{COOH}$ groups). Behind the wave, in the region of zero $-\mathrm{COOH}$ group concentration, the value of $q_{7}$ falls to zero as Reaction 7 ceases in the absence of $-\mathrm{COOH}$ (or $\mathrm{CF}_{2}$ ) groups. The large peaks correspond to rapid $\mathrm{HF}$ production in a region of high $\cdot \mathrm{OH}$ and $-\mathrm{COOH}$ concentration, as is evident from Fig. 5a and d. The $\mathrm{H}_{2} \mathrm{O}_{2}$ and $\cdot \mathrm{OH}$ concentrations reach a steady state early in their evolutions (before $t=28 \mathrm{~h}$ ). This is a consequence of the relaxation of the dissolved $\mathrm{O}_{2}$ and $\mathrm{H}_{2}$ concentration to steady-state profiles in a short period of time. To conserve space, these results are not shown.

Information regarding the rate and localization of $\mathrm{H}_{2} \mathrm{O}_{2}$ production is important for addressing the wider issue of the extent to which $\mathrm{H}_{2} \mathrm{O}_{2}$ is involved in degradation ${ }^{92,98}$ and, simultaneously, the feasibility of existing models. Evidence of preferential degradation at the cathode, rather than the anode, has been reported by several groups, ${ }^{25,80,36}$ and this discrepancy has yet to be explained fully. FER measurements depend strongly on the test procedure and the operating conditions, particularly the cell voltage, temperature, and $\mathrm{RH}$. At the $\mathrm{OCV}$, the rate of $\mathrm{H}_{2} \mathrm{O}_{2}$ production in the cathode is slow, even with significant levels of oxygen present. This is a consequence of the exponential dependence of Reaction 1 on the overpotential. Temperature and water activity determine the volume of liquid water present in the MEA. For a decreased temperature, decreased cell voltage, and increased water activity in the channels, the volume of water in the electrodes increases. These observations suggest that tests at the $\mathrm{OCV}$, high temperature, and low $\mathrm{RH}$ provide the most reliable data on $\mathrm{H}_{2} \mathrm{O}_{2}, \cdot \mathrm{OH}$, and HF production. Under these conditions, the volume, and therefore influence, of liquid water is minimal. Several investigations of the degradation rate at the OCV have revealed a sensitive dependence on the $\mathrm{O}_{2}$ partial pressure in the cathode channel, the membrane thickness, and the $\mathrm{O}_{2}$ concentration into the anode stream (oxygen bleeding). ${ }^{34,36,37,39}$ Aoki et al. demonstrated that the coexistence of $\mathrm{O}_{2}, \mathrm{H}_{2}$ and platinum catalyst is necessary for Nafion decomposition. ${ }^{34}$ At the OCV, the FER was measured for systems simulating cross leakage of $\mathrm{O}_{2}$ to the anode and, separately, cross leakage of $\mathrm{H}_{2}$ to the cathode. The FER was found to be much faster for cross leakage of $\mathrm{O}_{2}$, suggesting that the $\mathrm{H}_{2} \mathrm{O}_{2}$ is predominantly produced at the anode. Liu and Zuckerbrod found that the $\mathrm{H}_{2} \mathrm{O}_{2}$ concentration was inversely proportional to membrane thickness, i.e., the rate of gas crossover. ${ }^{39}$ The authors also argued that the anode conditions are far more conducive to 
(a)

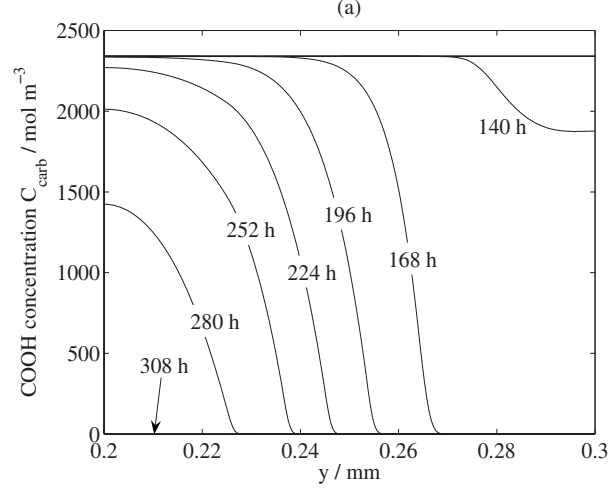

(c)

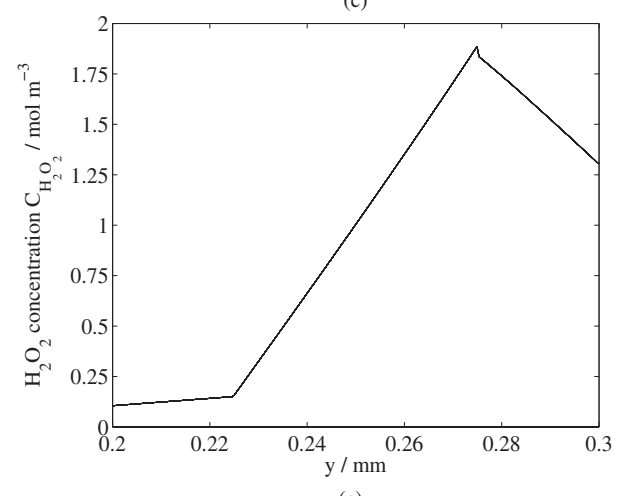

(e)

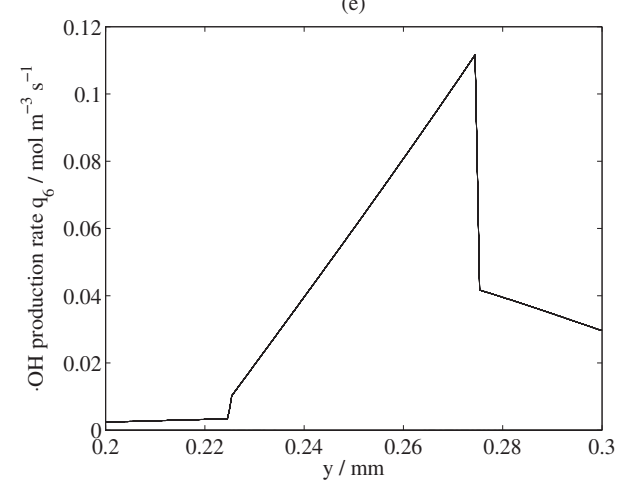

(b)

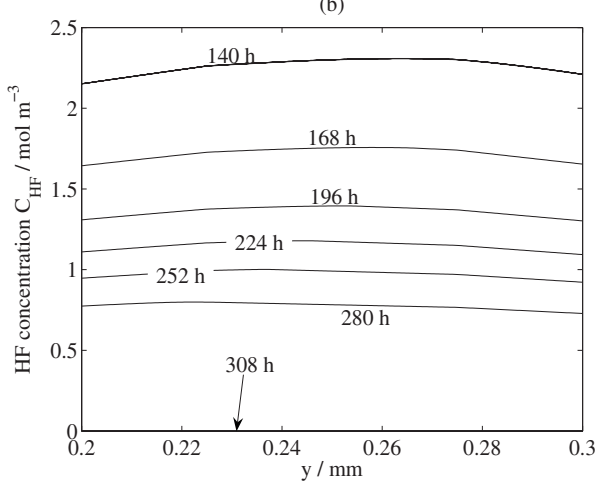

(d)

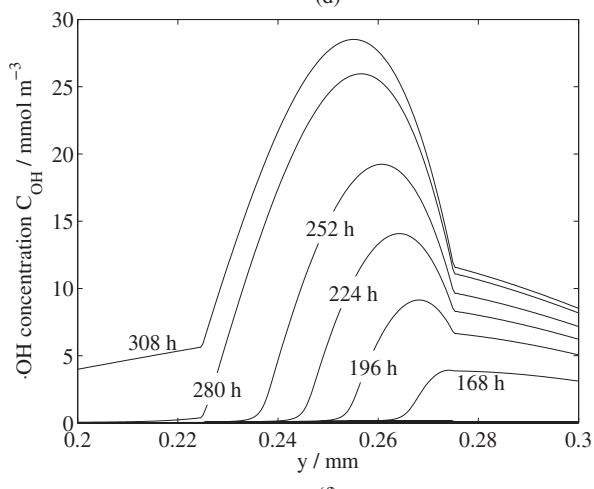

(f)

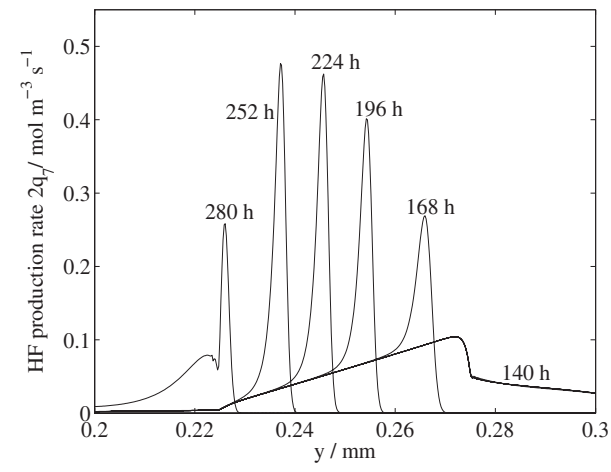

Figure 5. Evolutions of the concentrations of carboxylic acid, $\mathrm{HF}, \mathrm{H}_{2} \mathrm{O}_{2}$, and $\cdot \mathrm{OH}$, and the rates of reactions producing radicals and $\mathrm{HF}$ for the base-case parameter values at the OCV: $T_{\mathrm{A}}=T_{\mathrm{C}}=60^{\circ} \mathrm{C}$, $p_{\mathrm{g}, \mathrm{A}}=p_{\mathrm{g}, \mathrm{C}}=300 \mathrm{kPa}, \quad a_{\mathrm{w}, \mathrm{A}}=a_{\mathrm{w}, \mathrm{C}}=0.9$, no side-chain cleavage, and a constant $\mathrm{Fe}^{2+}$ concentration of $5 \mathrm{ppm}$. See Tables I, III, and VI-XI for the other parameter values. The CCL lies in the region $0.2<y$ $\leqslant 0.225$, the membrane lies in 0.225 $<y \leqslant 0.275$, and the ACL lies in 0.275 $<y \leqslant 0.3$.
$\mathrm{H}_{2} \mathrm{O}_{2}$ production than those at the cathode, where the large positive overpotential when operating near the OCV is prohibitive.

The plots in Fig. 5, arising from a model based on well-accepted mechanisms for $\mathrm{H}_{2} \mathrm{O}_{2}$ production, Reactions 1,4 , and 5, are consistent with preferential degradation at the anode. Figure $5 \mathrm{~b}$ also reveals that the HF concentration is close to uniform across the MEA, rising slightly toward the anode. Over the timescales considered, the $\mathrm{HF}$ is evenly distributed by diffusive transport through the membrane and ionomer. Moreover, the rate of production of HF changes qualitatively after the $\mathrm{CF}_{2}$, or equivalently the $-\mathrm{COOH}$, groups are exhausted in the ACL, coinciding with the onset of the wavelike behavior. The HF production rate is the most widely employed measure of degradation in accelerated and long-life tests. As the wave moves through the membrane from the anode to cathode, the rate of HF production on the anode side is practically zero. At $t=252 \mathrm{~h}$ and beyond, the HF concentration is higher at the cathode than at the anode. These results imply that FER may not be a reliable indicator of the evolution of chemical membrane degradation. The time at which the measurements are made is crucial; a lower FER in the anode may well be a consequence of complete degradation and not, as is typically assumed, a lack of degradation. Furthermore, as the simulation results demonstrate, transport by concentration gradients (diffusion), without the aid of water movement, redistributes the HF quite effectively. FER data must therefore be interpreted carefully when used as the basis for locating sites of major degradation and characterizing the progress of degradation through the MEA. As Fig. 5 shows, the concentration of $\cdot \mathrm{OH}$ is more indicative of the evolution of degradation. More so, the (steady) profiles of the rates of $\mathrm{H}_{2} \mathrm{O}_{2}$ and $\cdot \mathrm{OH}$ production represent good indicators of preferential degradation and the direction in which it will proceed, in the absence of other factors.

The evolution of the system for a reduced cathode-channel gas pressure of $p_{\mathrm{g}, \mathrm{C}}=200 \mathrm{kPa}$, with all other conditions and parameter values identical to those used in the base case in Fig. 5, is shown in Fig. 6. The decreased $\mathrm{O}_{2}$ concentration in the cathode leads to a slower rate of crossover to the anode and, therefore, a lower concentration of $\mathrm{H}_{2} \mathrm{O}_{2}$ and a slower rate of $\cdot \mathrm{OH}$ production, which can be seen by comparing Fig. 6a and b with Fig. 5c and e, respectively. As a consequence, the rate of degradation is decelerated. Compared with Fig. 5a and f, the profiles in Fig. $6 \mathrm{~b}$ and c, respectively, are retarded by approximately $140 \mathrm{~h}$; for $p_{g, \mathrm{C}}=300 \mathrm{kPa}$, degradation of the whole membrane is complete within $308 \mathrm{~h}$, whereas most of the membrane on the cathode side is intact after $308 \mathrm{~h}$ for $p_{g, \mathrm{C}}$ $=200 \mathrm{kPa}$. Furthermore, the rate of HF production is reduced by a factor of approximately two by the drop in gas pressure.

A similar result is found for a reduction in the membrane thickness, as demonstrated in Fig. 7, which shows the simulation results 

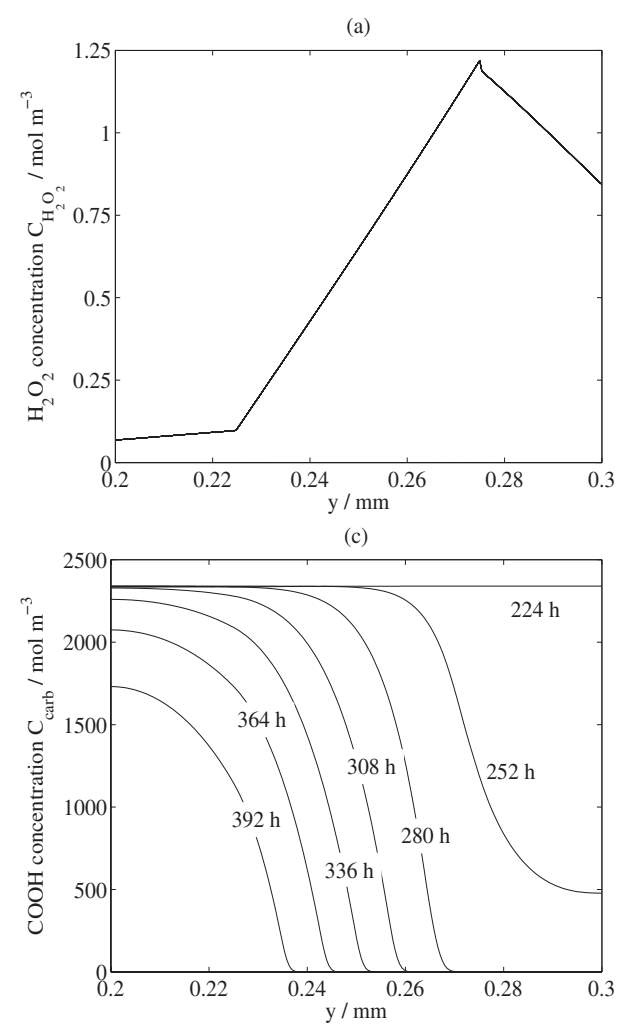
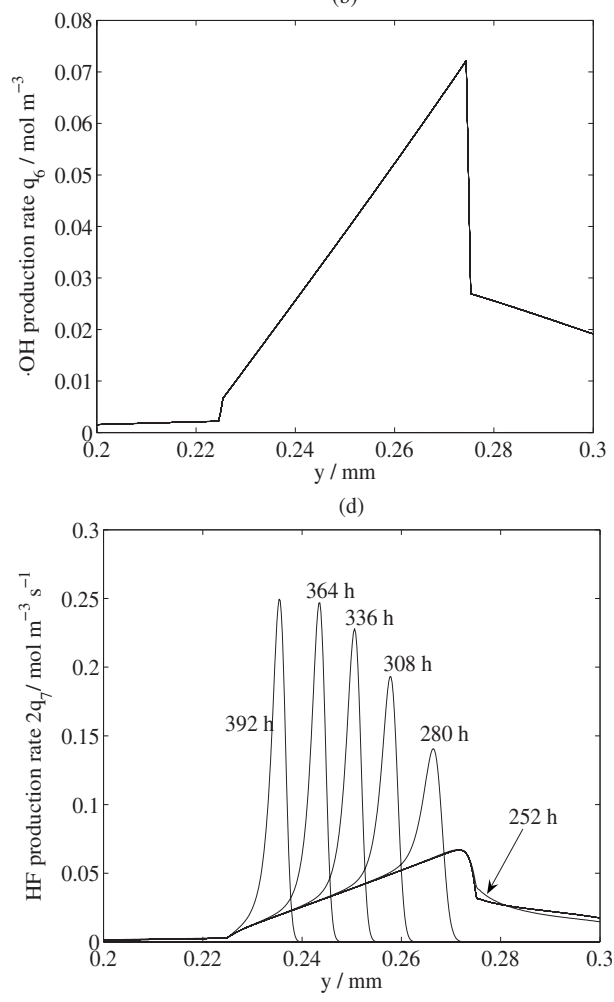

Figure 6. Evolution of the system at the OCV for a cathode-channel gas pressure $p_{\mathrm{g}, \mathrm{C}}=200 \mathrm{kPa}$, with all other parameter values identical to those for the base case in Fig. 5: $T_{\mathrm{A}}=T_{\mathrm{C}}=60^{\circ} \mathrm{C}, a_{\mathrm{w}, \mathrm{A}}=a_{\mathrm{w}, \mathrm{C}}$ $=0.9$, no side-chain cleavage, and a constant $\mathrm{Fe}^{2+}$ concentration of $5 \mathrm{ppm}$. See Tables I, III, and VI-XI for the remaining values. for a reduced membrane thickness of $L_{\mathrm{M}}=25 \mu \mathrm{m}$, with all other conditions and parameter values identical to those considered for the base case in Fig. 5. As before, the CCL lies in the region $0.2<y$ $\leqslant 0.225$, but now the membrane lies in $0.225<y \leqslant 0.25$ and the ACL in $0.25<y \leqslant 0.275$. The large increase in $\mathrm{H}_{2} \mathrm{O}_{2}$ concentration, comparing Fig. 7a with Fig. 5c, is in complete agreement with
Liu and Zuckerbrod's measurements of $\mathrm{H}_{2} \mathrm{O}_{2}$ evolution for a range of membrane thickness. ${ }^{39}$ An increased rate of $\mathrm{O}_{2}$ crossover to the anode for the thinner membrane increases the rate of $\mathrm{H}_{2} \mathrm{O}_{2}$ via $\mathrm{Re}$ action 5 and, consequently, the $\cdot \mathrm{OH}$ production rate, ultimately enhancing the degradation rate significantly.

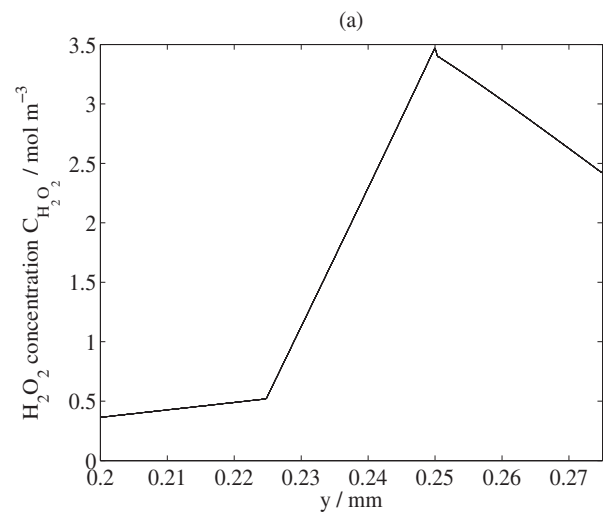

(c)

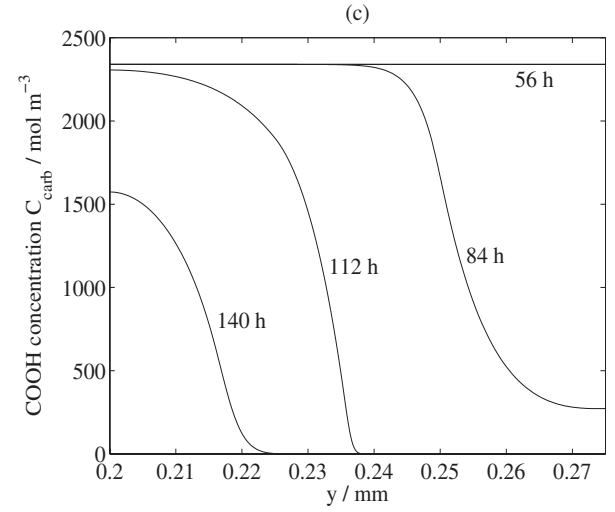

(b)

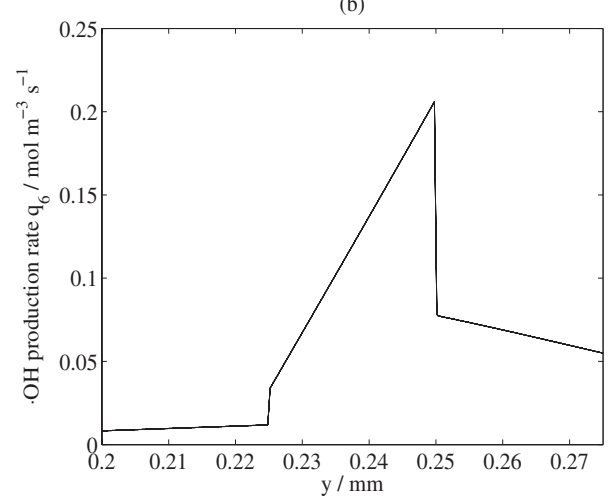

(d)

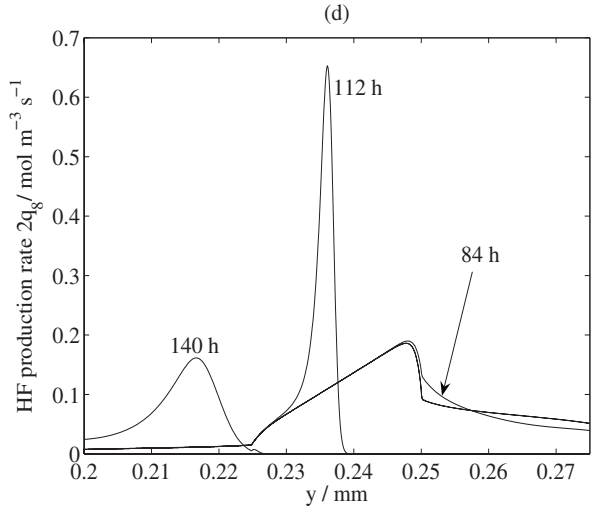

Figure 7. Evolution of the system at the OCV for membrane of thickness $L_{\mathrm{M}}$ $=25 \mu \mathrm{m}$, with all other parameter values identical to those for the base case in Fig. 5: $\quad T_{\mathrm{A}}=T_{\mathrm{C}}=60^{\circ} \mathrm{C}, \quad p_{\mathrm{g}, \mathrm{A}}=300 \mathrm{kPa}$, $a_{\mathrm{w}, \mathrm{A}}=a_{\mathrm{w}, \mathrm{C}}=0.9$, no side-chain cleavage, and a constant $\mathrm{Fe}^{2+}$ concentration of $5 \mathrm{ppm}$. See Tables I, III, and VI-XI for the remaining values. The CCL lies in the region $0.2<y \leqslant 0.225$, but now the membrane lies in $0.225<y \leqslant 0.25$ and the ACL in $0.25<y \leqslant 0.275$. 
(a)

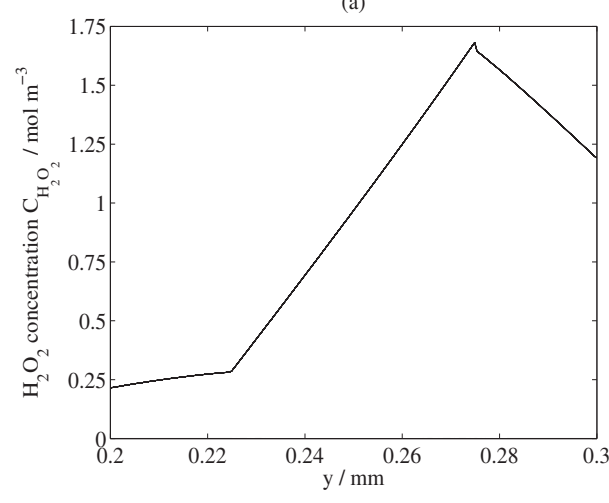

(c)

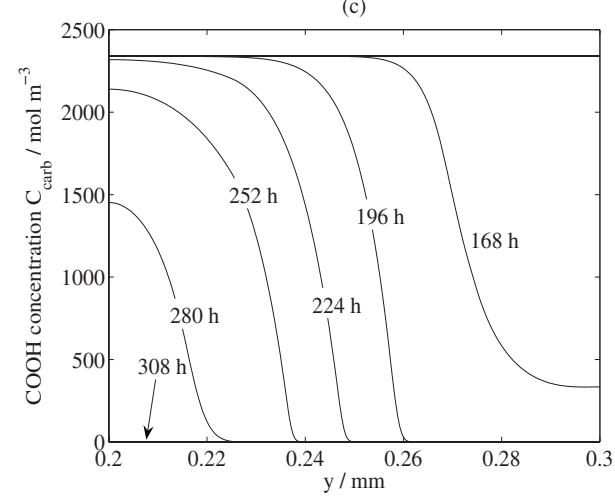

(b)

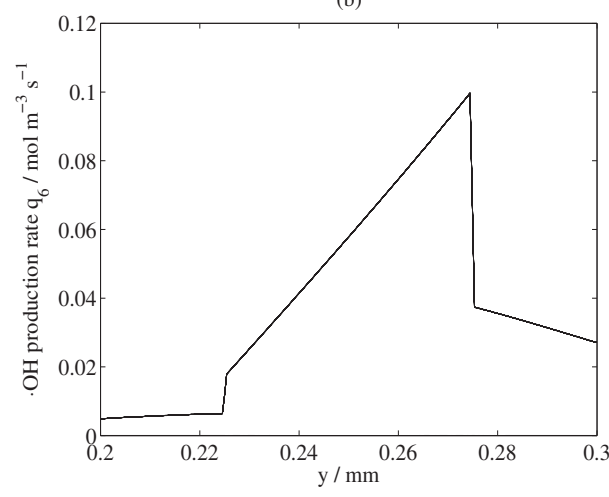

(d)

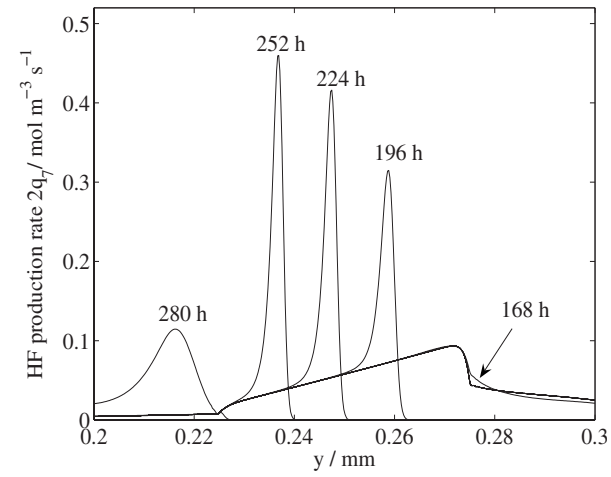

Figure 8. Evolution of the system for a cell voltage $E_{\text {cell }}=0.3 \mathrm{~V}$, with all other parameter values identical to those for the base case in Fig. 5: $T_{\mathrm{A}}=T_{\mathrm{C}}=60^{\circ} \mathrm{C}$, $p_{\mathrm{g}, \mathrm{A}}=p_{\mathrm{g}, \mathrm{C}}=300 \mathrm{kPa}, a_{\mathrm{w}, \mathrm{A}}=a_{\mathrm{w}, \mathrm{C}}=0.9$, no side-chain cleavage, and a constant $\mathrm{Fe}^{2+}$ concentration of $5 \mathrm{ppm}$. See Tables I, III, and VI-XI for the remaining values.
Degradation away from the OCV.- Figure 8 shows simulation results at a reduced cell voltage value of $E_{\text {cell }}=0.3 \mathrm{~V}$, with all other parameter values identical to those for the base case in Fig. 5 (see Tables I, III, and VI-XI).

A comparison of Fig. 8a with Fig. 5c reveals that the concentration of $\mathrm{H}_{2} \mathrm{O}_{2}$ in the anode is lower at $E_{\text {cell }}=0.3 \mathrm{~V}$, while the concentration in the cathode is higher. Accordingly, the rate of $\cdot \mathrm{OH}$ production is slower in the anode and faster in the cathode, which is seen by comparing Fig. 8b with Fig. 5e. Ultimately, the rate of degradation in the anode is slower at $E_{\text {cell }}=0.3 \mathrm{~V}$; the $-\mathrm{COOH}$ group profiles at $t=168$ and $196 \mathrm{~h}$ in Fig. 8c indicate a slower rate of progress of the wave when compared to the wave in Fig. 5a. As the wave reaches the cathode, its speed, i.e., the rate of membrane degradation, increases as a consequence of the faster rates of $\mathrm{H}_{2} \mathrm{O}_{2}$ and $\cdot \mathrm{OH}$ production in the cathode at $E_{\text {cell }}=0.3 \mathrm{~V}$ compared with the OCV. At $t=224 \mathrm{~h}$, a minimum in the $-\mathrm{COOH}$ concentration is attained at $y \approx 0.25 \mathrm{~mm}$ in both cases. By $t=280 \mathrm{~h}$, the progress of the wave at $E_{\text {cell }}=0.3 \mathrm{~V}$ is more advanced than that at the OCV.

It has been reported by Mittal et al. and Inaba et al., among other groups, that chemical degradation is less severe at cell voltages below the OCV. ${ }^{98,99}$ The result above, however, suggests a more subtle link; the rate of degradation is initially decreased, but as degradation advances there is little difference between the two cases in Fig. 5 and 8 . The duration of the test and the times at which measurements are taken are important. The commonly accepted explanation for the link between cell voltage and degradation is the increased $\mathrm{O}_{2}$ consumption at a nonzero current, which reduces the rate of $\mathrm{O}_{2}$ crossover, thereby decreasing the rate of $\mathrm{H}_{2} \mathrm{O}_{2}$ production at the anode. ${ }^{34,36}$ As Mittal et al. point out, increased degradation for increased cell voltage is contrary to what would be expected from a mechanism that is based on radical formation predominantly from the two-electron oxygen reduction at the cathode (Reaction 1). ${ }^{92}$ Indeed, the observed relationship between degradation and cell voltage provides further evidence of preferential degradation at the anode, initiated by radicals that are formed as a result of $\mathrm{O}_{2}$ crossover and peroxide formation according to Reaction 5 .

A comparison of Fig. 8a and 5c does demonstrate that a lower cell voltage (increased current) leads to an increased rate of $\mathrm{H}_{2} \mathrm{O}_{2}$ production in the cathode through Reaction 1 . This is to be expected, because a nonzero current lowers the overpotential $\eta_{1}$ in Eq. 41 . Because the majority of radicals are produced at the anode from $\mathrm{O}_{2}$ crossover, and the evolution of degradation is from anode to cathode, the effects of increased $\mathrm{H}_{2} \mathrm{O}_{2}$ and radical concentrations in the cathode are not significant until the portion of the membrane on the anode side has degraded. Initially, the reduced cell voltage leads to a reduced $\mathrm{O}_{2}$ crossover, which reduces the rate of degradation, in agreement with the experimental results. ${ }^{98,99}$

Effects of channel temperature and water activity. - It is widely accepted that degradation can be enhanced at a higher temperature and a lower RH, ${ }^{15-17,23,34,35,67}$ although the reasons for these trends are not entirely understood. Figure 9 shows simulation results at the OCV for reduced channel water activities of $a_{\mathrm{w}, \mathrm{A}}=a_{\mathrm{w}, \mathrm{C}}=0.2$, with all other parameter values identical to those considered in the base case in Fig. 5 (see Tables I, III, and VI-XI). The $\mathrm{H}_{2} \mathrm{O}_{2}$ concentration increases by approximately $10 \%$ and the rate of production of $\cdot \mathrm{OH}$ by approximately $35 \%$ for the case with a lower water activity; compare Fig. 9a and b with Fig. $5 c$ and e, respectively. The differences are more clearly seen in Table XII which gives the average steady-state values of the $\mathrm{H}_{2} \mathrm{O}_{2}$ concentration and the $\cdot \mathrm{OH}$ production rate in the anode and cathode, for both the base case in Fig. 5 and the case $a_{\mathrm{w}, \mathrm{A}}=a_{\mathrm{w}, \mathrm{C}}=0.2$ in Fig. 9. The averages are defined by

$$
\left\langle q_{6 \mathrm{a}}\right\rangle=\frac{1}{L_{\mathrm{C}}} \int q_{6 \mathrm{a}} d x, \quad\left\langle c_{\mathrm{H}_{2} \mathrm{O}_{2}}\right\rangle=\frac{1}{L_{\mathrm{C}}} \int c_{\mathrm{H}_{2} \mathrm{O}_{2}} d x
$$

where $L_{\mathrm{C}}$ is the thickness of the CLs and the integrals are taken over the anode or cathode CLs.

Figure 9c and d, compared to Fig. 5a and f, respectively, shows that the degradation is enhanced by the reduction in channel water activities, as experimental studies have demonstrated. Variations in water activity have several consequences. First, the decrease in cathode water activity increases the rate of $\mathrm{H}_{2} \mathrm{O}_{2}$ production by Reaction 

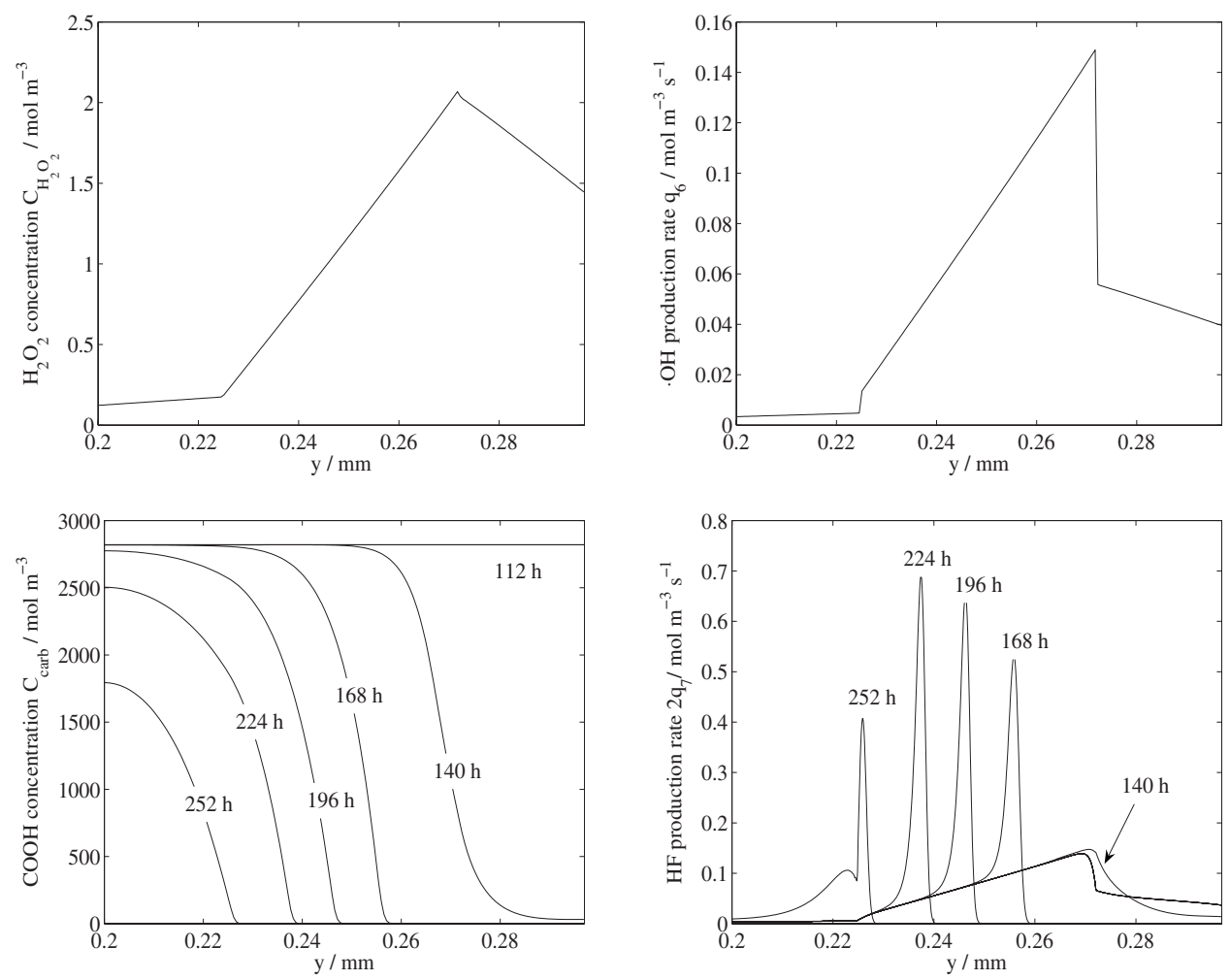

Figure 9. Evolution of the system at the OCV for channel water activities $a_{\mathrm{w}, \mathrm{A}}$ $=a_{\mathrm{w}, \mathrm{C}}=0.2$, with all other parameter values identical to those for the base case in Fig. 5: $T_{\mathrm{A}}=T_{\mathrm{C}}=60^{\circ} \mathrm{C}, \quad p_{\mathrm{g}, \mathrm{A}}=p_{\mathrm{g}, \mathrm{C}}$ $=300 \mathrm{kPa}$, no side-chain cleavage, and a constant $\mathrm{Fe}^{2+}$ concentration of $5 \mathrm{ppm}$. See Tables I, III, and VI-XI for the remaining values.
1, given in Eq. 41 through an increase in the proton concentration $(\mathrm{pH})$ given by Eq. 60 and 61; at a water activity of 0.9 , the density of Nafion is approximately $1506 \mathrm{~kg} \mathrm{~m}^{-3}$, and at a water activity of 0.2 , the density is approximately $1815 \mathrm{~kg} \mathrm{~m}^{-3}$. The increased density leads to a reduction in the volume of the membrane to conserve mass. The thickness of the membrane (assuming equal variation in each dimension) is therefore given by the original value of $50 \mu \mathrm{m}$ multiplied by $(1506 / 1815)^{1 / 3}=0.94$, that is, $47 \mu \mathrm{m}$.

As seen from the values in Table XII, the increase in $\mathrm{H}_{2} \mathrm{O}_{2}$ concentration in the cathode is only on the order of $10 \%$. The increase in the rate of radical production, however, is on the order of $35 \%$ in both the cathode and ACLs. This cannot be due entirely to the modest increase in the $\mathrm{H}_{2} \mathrm{O}_{2}$ concentration. The main reason for the enhanced degradation at lower water activity is the increased concentration of $\mathrm{Fe}^{2+}$, given by Eq. 63 as a result of the $20.5 \%$ increase in the density of the Nafion. In other words, the mass of Nafion per unit volume leads to an increase in the mass of $\mathrm{Fe}^{2+}$ per unit volume, which increases the rate of Reaction 6a. There is a concomitant increase in the initial concentrations of $-\mathrm{COOH}$ groups, weak polymer end groups, and $\mathrm{CF}_{2}$ groups. In the calculations leading to Fig. 9, the initial values were therefore given by those in Table VII multiplied by a factor of 1.205.

Figure 10 shows simulation results at the $\mathrm{OCV}$ for increased channel temperatures of $T_{\mathrm{A}}=T_{\mathrm{C}}=80^{\circ} \mathrm{C}$, with all other parameter values identical to those for the base case in Fig. 5 (see Tables I, III,

Table XII. The spatially averaged steady-state values of the $\mathrm{H}_{2} \mathrm{O}_{2}$ concentration and the $\mathrm{OH}$ production rate for both the base case in Fig. 5 and for water activities of 0.2, corresponding to Fig. 9.

\begin{tabular}{cccccc} 
& \multicolumn{2}{c}{ Anode } & & \multicolumn{2}{c}{ Cathode } \\
\cline { 2 - 3 } \cline { 5 - 6 } Water activity & $\begin{array}{c}\left\langle c_{\mathrm{H}_{2} \mathrm{O}_{2}}\right\rangle \\
\left(\mathrm{mol} \mathrm{m}^{-3}\right)\end{array}$ & $\begin{array}{c}\left\langle q_{6 a}\right\rangle \\
\left(\mathrm{mol} \mathrm{m}^{-3} \mathrm{~s}^{-1}\right)\end{array}$ & & $\begin{array}{c}\left\langle c_{\mathrm{H}_{2} \mathrm{O}_{2}}\right\rangle \\
\left(\mathrm{mol} \mathrm{m}^{-3}\right)\end{array}$ & $\begin{array}{c}\left\langle q_{6 a}\right\rangle \\
\left(\mathrm{mol} \mathrm{m}^{-3} \mathrm{~s}^{-1}\right)\end{array}$ \\
\hline 0.9 & 1.585 & 0.036 & & 0.128 & 0.0029 \\
0.2 & 1.660 & 0.045 & & 0.133 & 0.0036
\end{tabular}

and VI-XI). In agreement with experimental observations, increasing the temperature by $20^{\circ} \mathrm{C}$ has a significant effect on the rate of degradation. ${ }^{28,100}$ Chen et al. ${ }^{28}$ reported a fourfold increase in the FER as a result of increasing the temperature from 60 to $80^{\circ} \mathrm{C}$ in Fenton tests. Sethuraman et al. performed in situ the OCV decay tests and found that cells operating at 80,100 , and $120^{\circ} \mathrm{C}$ failed after 498,56 , and $<25 \mathrm{~h}$, respectively. ${ }^{100}$

A comparison of Fig. 10a and b with Fig. 10c and e, respectively, reveals a twofold increase in the steady-state rate of $\cdot \mathrm{OH}$ production and a slight reduction in the steady-state concentration of $\mathrm{H}_{2} \mathrm{O}_{2}$. The reduction in the $\mathrm{H}_{2} \mathrm{O}_{2}$ concentration is due to a decrease in the $\mathrm{O}_{2}$ and $\mathrm{H}_{2}$ concentrations in the cathode and anode channels, respectively, as a result of the temperature rise at constant pressure. The $\mathrm{O}_{2}$ concentration decreases from 21.41 to $18.46 \mathrm{~mol} \mathrm{~m}^{-3}$, which, despite an increase in the diffusion coefficient of $\mathrm{O}_{2}$ through the membrane according to Eq. 6, reduces the rate of crossover to the anode. The decreased rate of crossover outweighs the increase in the rate constant for Reaction 5 through the Arrhenius form (Eq. 62) and results in lower levels of $\mathrm{H}_{2} \mathrm{O}_{2}$ in the anode. The rate of Reaction 6a, however, increases substantially, again as a consequence of the Arrhenius form of the rate constant $r_{6 \mathrm{a}}$. Figure $10 \mathrm{c}$ and $\mathrm{d}$, when compared to Fig. 5a and f, respectively, shows that both the rate of degradation and the release of HF increase dramatically, matching both in situ and ex situ experimental results. ${ }^{28,100}$

Rate of degradation and side-chain cleavage.- The rate constants for Reactions 7-10 are not known, and in this work their values have been assumed. In all of the preceding results, a value of $1000 \mathrm{~m}^{6} \mathrm{~mol}^{-2} \mathrm{~s}^{-1}$ was used for Reaction 7. Figure 11 compares simulations at the $\mathrm{OCV}$ for a range of $r_{7}$ values, with all other parameter values as in Tables I, III, and VI-XI. The main conclusion from these calculations is that the basic behavior observed in Fig. 5, in which $r_{7}=1000 \mathrm{~m}^{6} \mathrm{~mol}^{-2} \mathrm{~s}^{-1}$, is robust to changes in the value of $r_{7}$. The wavelike behavior is not affected; the speed of the wave is merely increased or decreased for an increase or decrease, respectively, in the value of $r_{7}$

The side-chain cleavage (Reaction 9) and the associated decomposition of molecule A (Reaction 10) are generally considered to 


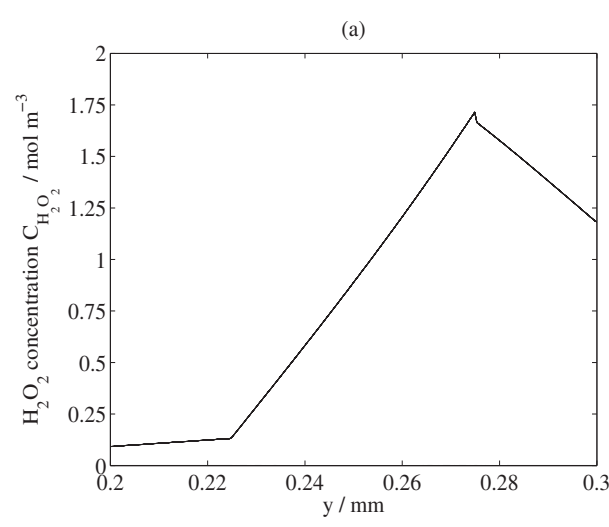

(c)

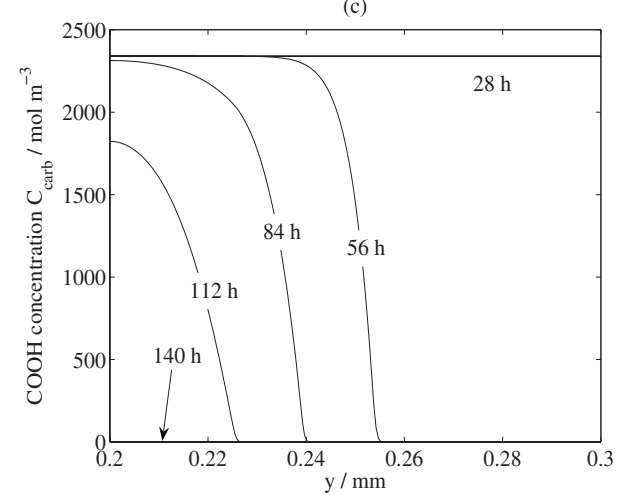

(b)

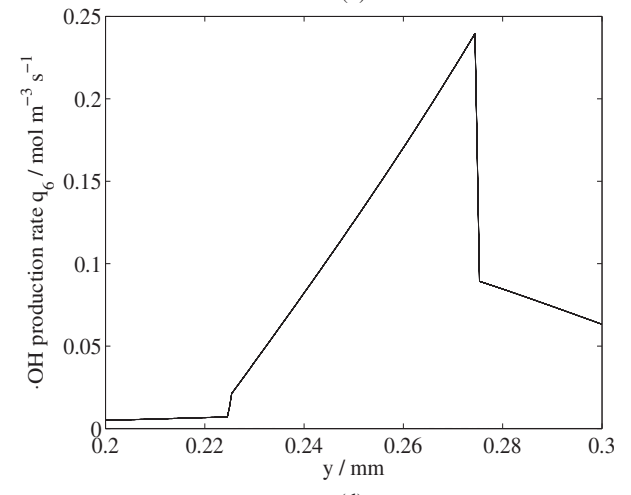

(d)

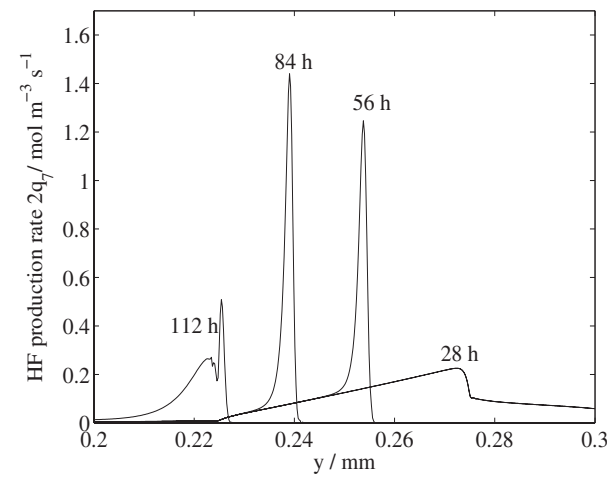

Figure 10. Evolution of the system at the OCV for channel temperatures $T_{\mathrm{A}}=T_{\mathrm{C}}$ $=80^{\circ} \mathrm{C}$, with all other parameter values identical to those for the base case in Fig. 5: $\quad p_{\mathrm{g}, \mathrm{A}}=p_{\mathrm{g}, \mathrm{C}}=300 \mathrm{kPa}, \quad a_{\mathrm{w}, \mathrm{A}}=a_{\mathrm{w}, \mathrm{C}}$ $=0.9$, no side-chain cleavage, and a constant $\mathrm{Fe}^{2+}$ concentration of $5 \mathrm{ppm}$. See Tables I, III, and VI-XI for the remaining values. have a secondary influence on the degradation of PFSA membranes. A plot of FER against - $\mathrm{COOH}$ group content in Nafion exhibits a nonzero intercept, ${ }^{33}$ suggesting that up to $10 \%$ of the fluoride is generated from a mechanism other than Reaction 7 . The presence of molecule $\mathrm{A}$ in effluent water has been reported by several groups, ${ }^{12,15,27,33}$ further suggesting that side-chain cleavage is one origin of the additional fluoride. In order to match the figure of $10 \%$, it was found that a value of $r_{9}=O(1)$ was required.

Figure 12 shows simulation results at the OCV with $r_{9}=r_{10}$ $=1 \mathrm{~mol}^{-1} \mathrm{~m}^{3} \mathrm{~s}^{-1}$, with all other parameter values identical to those for the base case in Fig. 5, given in Tables I, III, and VI-XI. The side-chain groups are rapidly depleted in comparison to the rate of $-\mathrm{COOH}$ group depletion, as seen by comparing Fig. 12a and c. Cleavage of the side chains and degradation of molecule A lead to the formation of additional $-\mathrm{COOH}$ groups, so that the initial rise in the $-\mathrm{COOH}$ group concentration is well above that in Fig. 5, where side-chain cleavage is not included. The preponderance of $\cdot \mathrm{OH}$ at
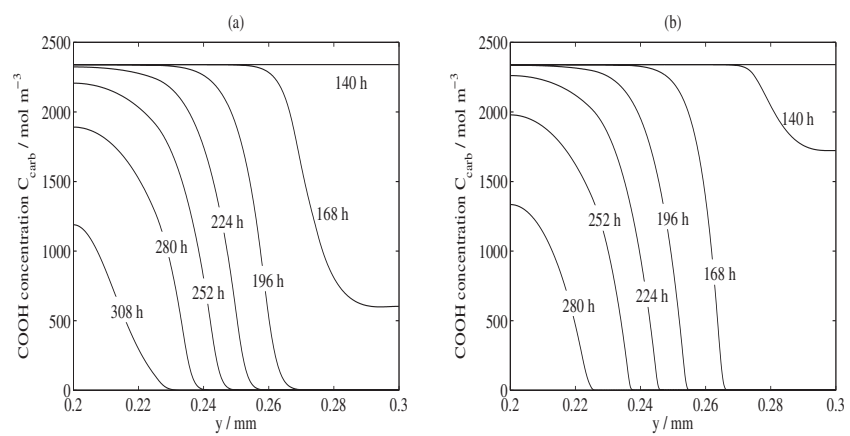

Figure 11. Evolution of the $-\mathrm{COOH}$ group concentration at the $\mathrm{OCV}$ with (a) $r_{7}=10 \mathrm{~m}^{6} \mathrm{~mol}^{-2} \mathrm{~s}^{-1}$, and (b) $r_{7}=1 \times 10^{4} \mathrm{~m}^{6} \mathrm{~mol}^{-2} \mathrm{~s}^{-1}$. All other parameter values are identical to those for the base case in Fig. 5: $p_{\mathrm{g}, \mathrm{A}}$ $=p_{\mathrm{g}, \mathrm{C}}=300 \mathrm{kPa}, a_{\mathrm{w}, \mathrm{A}}=a_{\mathrm{w}, \mathrm{C}}=0.9, T_{\mathrm{A}}=T_{\mathrm{C}}=80^{\circ} \mathrm{C}$, no side-chain cleavage, and a constant $\mathrm{Fe}^{2+}$ concentration of 5 ppm. See Tables I, III, and VI-XI for the remaining values. the anode, as before, leads to preferential side-group depletion at the anode. The profile in the $-\mathrm{COOH}$ concentration at $28 \mathrm{~h}$ in Fig. 12c shows that the maximum $-\mathrm{COOH}$ group concentration is rapidly attained at the anode. Thereafter, the $-\mathrm{COOH}$ group concentration begins to decay. Figure $12 \mathrm{~d}$ and $\mathrm{b}$ shows that the ratio of the formation rate of $\mathrm{HF}$ by the unzipping mechanism (Reaction 7) to that by side-chain cleavage reaction (Reaction 9) is approximately 1:10, as required.

The profiles of $-\mathrm{COOH}$ concentration and of $2 q_{7}$ show that the wavelike motion seen in all previous results persists with side-chain cleavage included, albeit at a slower rate compared to the wave in Fig. 5a as a result of the increased maximum in the $-\mathrm{COOH}$ concentration. The side-chain concentration also decays in a wavelike manner at a more rapid rate; the decay is limited primarily by the local concentration of $\cdot \mathrm{OH}$.

\section{Conclusions}

A framework for modeling the chemical degradation of a PFSA membrane inside a PEM fuel cell has been developed. Within the framework, several extensions to this first model are possible, primarily in relation to the kinetics of both peroxide/radical formation and membrane attack. At the present time, however, there is no consensus on the mechanisms for these processes. A central objective of this work is to gain a better understanding of the physicoelectrochemical steps that lead to membrane degradation. The initial focus has been placed on those mechanisms that are best supported by experimental evidence, or most widely accepted, in order to assess their ability to explain observed trends in a consistent fashion.

The parametric studies performed in this paper have revealed several features of the degradation behavior that are potentially important to achieving a better understanding of the steps and processes involved, particularly of the role of peroxide and radicals.

$\mathrm{H}_{2} \mathrm{O}_{2}$ is generated predominantly at the anode by Reaction 5, facilitated by $\mathrm{O}_{2}$ crossover from the cathode to anode. Formation of appreciable rates of $\mathrm{H}_{2} \mathrm{O}_{2}$ in the cathode at the $\mathrm{OCV}$ is prevented by a large positive overpotential. The rate of crossover controls the rate of $\mathrm{H}_{2} \mathrm{O}_{2}$ production. Decreasing the membrane thickness and in- 


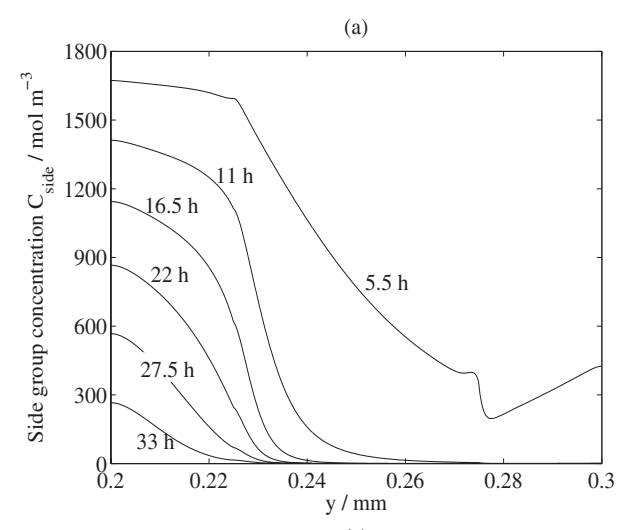

(c)

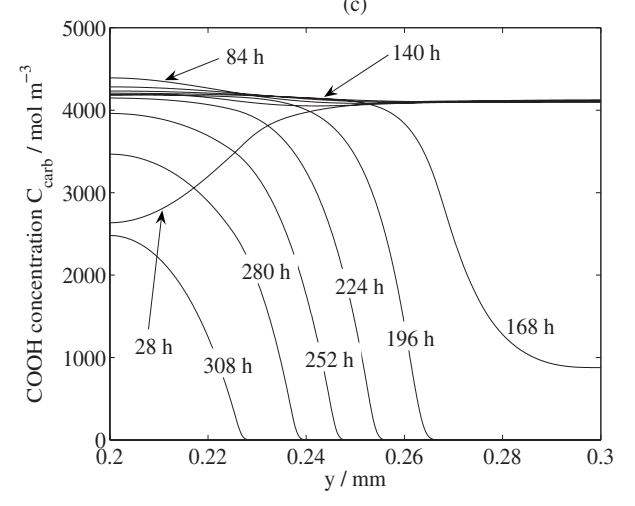

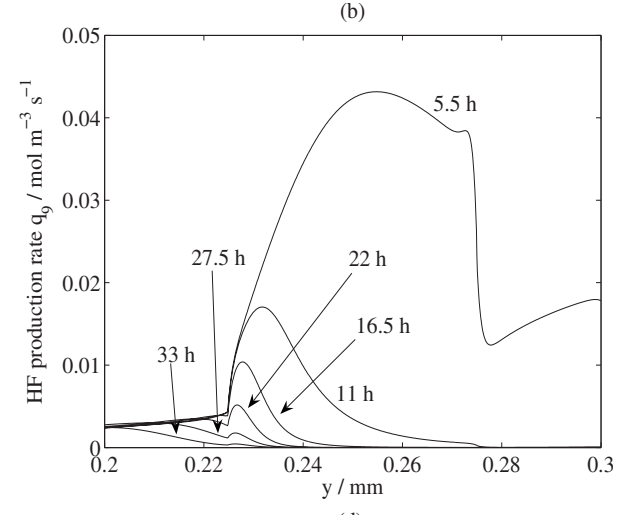

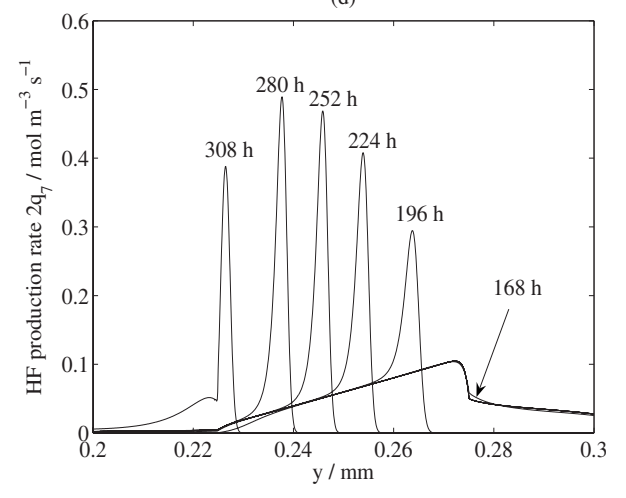

Figure 12. Evolution of the system at the OCV with side-chain cleavage included: $r_{9}=r_{10}=1 \mathrm{~mol}^{-1} \mathrm{~m}^{3} \mathrm{~s}^{-1}$. The other parameter values are identical to those for the base case in Fig. 5: $p_{\mathrm{g}, \mathrm{A}}=p_{\mathrm{g}, \mathrm{C}}$ $=300 \mathrm{kPa}, \quad a_{\mathrm{w}, \mathrm{A}}=a_{\mathrm{w}, \mathrm{C}}=0.9$, no sidechain cleavage, and a constant $\mathrm{Fe}^{2+}$ concentration of $5 \mathrm{ppm}$. See Tables I, III, and VI-XI for the remaining values. creasing the $\mathrm{O}_{2}$ partial pressure in the cathode stream can dramatically increase the rate, consistent with a model of $\mathrm{H}_{2} \mathrm{O}_{2}$ production mainly at the anode.

The rate of radical formation increases substantially with temperature and impurity concentration and is correlated to the rate of $\mathrm{H}_{2} \mathrm{O}_{2}$ formation. The effect of a decrease in the rate of $\mathrm{H}_{2} \mathrm{O}_{2}$ formation on the rate of degradation can be outweighed by a increase in the rate of radical formation, through its highly sensitive dependence on temperature (compare Fig. 5 and 10). A decrease in water activity is known to increase the rate of degradation. There are two effects that contribute to this phenomenon: $(i)$ an increased rate of $\mathrm{H}_{2} \mathrm{O}_{2}$ production in the cathode by Reaction 1 through an increase in the proton concentration and (ii) an increase in the concentration of metal-ion impurities as a consequence of the increased membrane density. Effect $i i$ is by far the predominant factor leading to the increased rate of degradation.

Degradation of the membrane (depletion of the $-\mathrm{COOH}$ and $\mathrm{CF}_{2}$ groups) proceeds in a wavelike manner, as seen in, for example, Fig. $5 \mathrm{a}$. The direction of propagation is invariably from the anode to cathode. For a decreasing cell voltage, the rate of $\mathrm{O}_{2}$ consumption in the cathode increases, which reduces the rates of $\mathrm{O}_{2}$ crossover and $\mathrm{H}_{2} \mathrm{O}_{2}$ formation at the anode. The degradation rate is, therefore, decreased. However, as the degradation front approaches the cathode, its speed increases because the rate of $\mathrm{H}_{2} \mathrm{O}_{2}$ formation at the cathode is enhanced by a reduction in the cell voltage. The values of the rate constants for the degradation reactions were varied in order to demonstrate that the wavelike behavior persists over a broad range of unknown parameter values. The speed of the wave front varies with changes in the values of $r_{7}$ and $r_{9}$, but there are no qualitative differences. These rate constants could in principle be measured with in situ carbon-fluorine NMR (high field) to follow the unzipping of the chain. It is important to acknowledge, however, the problem of extreme sensitivity for any analytical method.

The most widely employed measure of the degradation rate is the FER. Numerical simulations have demonstrated that the use of FER to investigate preferential degradation could lead to erroneous conclusions. The generation of HF is highly localized, as demonstrated in Fig. 5f, and the peak in HF production follows the degradation front from the anode to the cathode. Moreover, diffusive transport redistributes the HF quite effectively across the MEA. The times at which the measurements are taken are important; a low concentration of HF may well be a result of complete degradation rather than a lack of degradation. The $\mathrm{H}_{2} \mathrm{O}_{2}$ and $\cdot \mathrm{OH}$ concentrations (for example, Fig. 5c and d) provide better indicators of preferential degradation.

Southampton University assisted in meeting the publication costs of this article.

\section{List of Symbols}

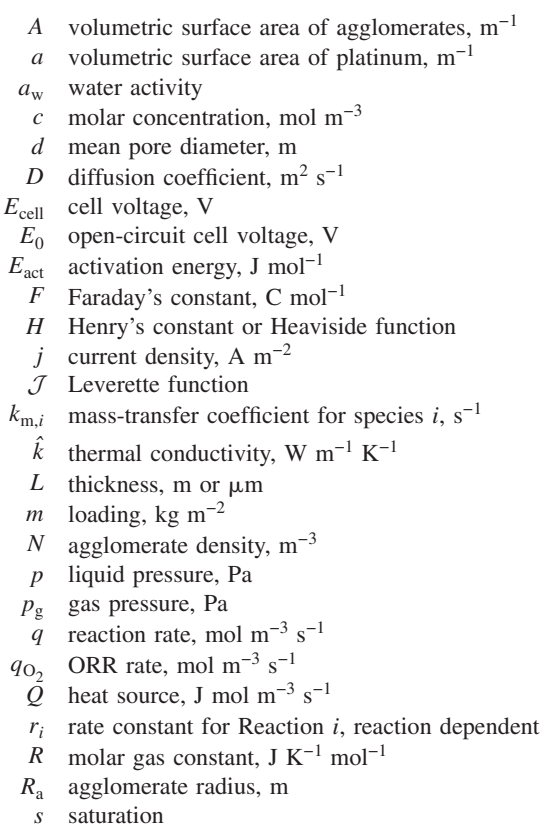


$s_{*}$ immobile saturation

$S$ source term, $\mathrm{mol} \mathrm{m}^{-3} \mathrm{~s}^{-1}$ or $\mathrm{W} \mathrm{m} \mathrm{m}^{-3}$ or $\mathrm{A} \mathrm{m}^{-3}$

$t$ time, s

$T$ temperature, $\mathrm{K}$

$v$ velocity, $\mathrm{m} \mathrm{s}^{-1}$

$M$ molar mass, $\mathrm{kg} \mathrm{mol}^{-1}$

$x$ mole fraction

$y$ distance, $\mathrm{m}$

Greek

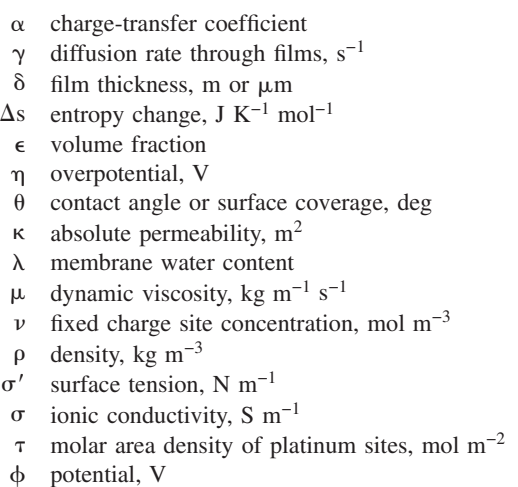

Subscripts

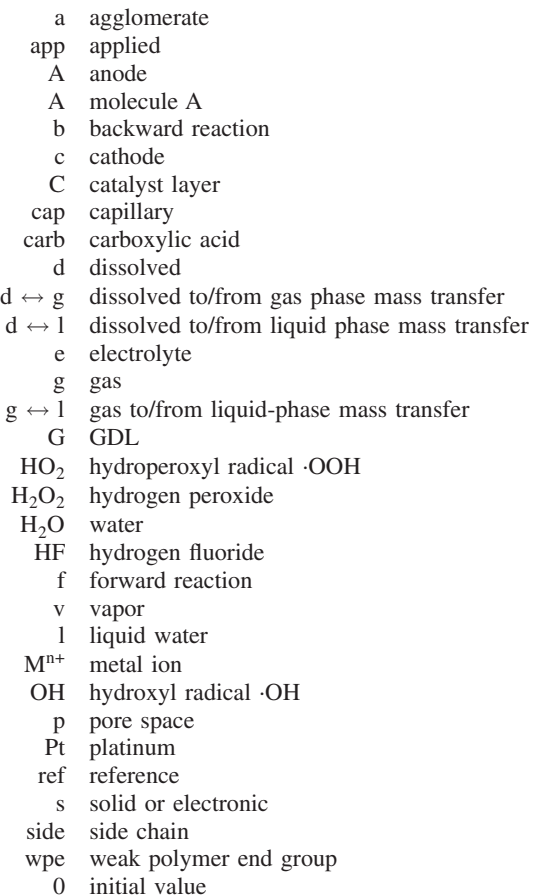

Superscripts

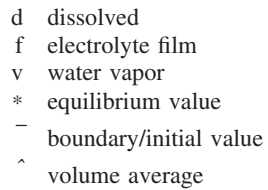

\section{References}

1. W. Schmittinger and A. Vahidi, J. Power Sources, 180, 1 (2008).

2. T. Springer, T. Rockward, T. Zawodzinski, and S. Gottesfeld, J. Electrochem. Soc., 148, A11 (2001)

3. T. Loučka, J. Electroanal. Chem. Interfacial Electrochem., 31, 319 (1971).

4. T. Loučka, J. Electroanal. Chem. Interfacial Electrochem., 36, 369 (1972)

5. A. Q. Contractor and H. Lal, J. Electroanal. Chem. Interfacial Electrochem., 96, 175 (1979).

6. X. Cheng, Z. Shi, N. Glass, L. Zhang, J. Zhang, D. Song, Z.-S. Liu, H. Wang, and J. Shen, J. Power Sources, 165, 739 (2007).

7. M. S. Wilson, F. H. Garzon, K. E. Sickafus, and S. Gottesfeld, J. Electrochem. Soc., 140, 2872 (1993).
8. R. Borupa, J. Daveya, F. Garzona, D. Wooda, and M. Inbody, J. Power Sources, 163, 76 (2006)

9. S. Maass, F. Finsterwalder, G. Frank, R. Hartmann, and C. Merten, J. Power Sources, 176, 444 (2008).

10. J. Meyers and R. Darling, J. Electrochem. Soc., 153, A1432 (2006),

11. A. Collier, H. Wang, X. Yuan, J. Zhang, and D. Wilkinson, Int. J. Hydrogen Energy, 31, 1838 (2006).

12. D. Schiraldi, Polym. Rev., 46, 315 (2006).

13. W. Liu, K. Ruth, and G. Rusch, J. New Mater. Electrochem. Syst., 4, 227 (2001).

14. C. Huang, K. Tan, and J. Lin, Chem. Phys. Lett., 371, 80 (2003).

15. J. Healy, C. Hayden, T. Xie, K. Olson, R. Waldo, M. Brundage, H. Gasteiger, and J. Abbot, Fuel Cells, 5, 302 (2005).

16. E. Endoh, S. Terazono, H. Widjaja, and Y. Takimoto, Electrochem. Solid-State Lett., 7, A209 (2004).

17. S. Knights, K. Colbow, J. St-Pierre, and D. Wilkinson, J. Power Sources, 127, 127 (2004).

18. D. Jones and J. Rozière, J. Membr. Sci., 185, 41 (2001).

19. C. Iojoiu, E. Guilminot, F. Maillard, M. Chatenet, J.-Y. Sanchez, E. Claude, and E. Rossinot, J. Electrochem. Soc., 154, B1115 (2007).

20. A. Taniguchi, T. Akita, K. Yasuda, and Y. Miyazaki, J. Power Sources, 130, 42 (2004).

21. M. Pianca, E. Barchiesi, G. Esposto, and S. Radice, J. Fluorine Chem., 95, 71 (1999).

22. D. Curtin, R. Lousenberg, T. Henry, P. Tangeman, and M. Tisack, J. Power Sources, 131, 35 (2004).

23. A. LaConti, M. Hamdan, and R. McDonald, in Handbook of Fuel CellsFundamentals, Technology and Applications, Vol. 3, A. L. W. Vielstich and H. Gasteiger, Editors, pp. 647-662, John Wiley \& Sons, New York (2003).

24. W. Bi, G. Gray, and T. Fuller, Electrochem. Solid-State Lett., 10, B101 (2007).

25. A. Pozio, R. Silva, M. De Francesco, and L. Giorgi, Electrochim. Acta, 48, 1543 (2003).

26. J. Xie, D. L. Wood III, D. M. Wayne, T. A. Zawodzinski, P. Atanassov, and R. L. Borup, J. Electrochem. Soc., 152, A104 (2005)

27. T. Xie and C. Hayden, Polymer, 48, 5947 (2007).

28. C. Chen, G. Levitin, D. Hess, and T. Fuller, J. Power Sources, 169, 288 (2007).

29. V. Sethuraman, J. Weidner, A. Haung, S. Motupally, and L. Protsailo, J. Electrochem. Soc., 155, B50 (2008)

30. X. Huang, R. Solasi, Y. Zou, M. Feshler, K. Reifsnider, D. Condit, S. Burlatsky, and T. Madden, J. Polym. Sci., Part B: Polym. Phys., 44, 2346 (2006).

31. C.-Y. Wang, Chem. Rev. (Washington, D.C.), 104, 4727 (2004).

32. A. Weber and J. Newman, Chem. Rev. (Washington, D.C.), 104, 4679 (2004),

33. K. Schwiebert, K. Raiford, G. Nagarajan, F. Principe, and G. Escobedo, in Proceedings of the Knowledge Foundation Technology Commercialization Alliance International Symposium, Washington, DC (2005).

34. M. Aoki, H. Uchida, and M. Watanabe, Electrochem. Commun., 7, 1434 (2005).

35. H. A. Gasteiger, W. Gu, R. Makharia, M. Mathias, and B. Sompalli, in Handbook of Fuel Cells-Fundamentals, Technology and Applications, Vol. 3, A. W. Vielstich and H. Gasteiger, Editors, pp. 593-610, John Wiley \& Sons, New York (2003).

36. M. Inaba, T. Kinumoto, M. Kiriake, R. Umebayashi, A. Tasaka, and Z. Ogumi, Electrochim. Acta, 51, 5746 (2006).

37. M. Aoki, H. Uchida, and M. Watanabe, Electrochem. Commun., 8, 1509 (2006).

38. L. Merlo, A. Ghielmi, L. Cirillo, M. Gebert, and V. Arcella, J. Power Sources, 141, 140 (2007).

39. W. Liu and D. Zuckerbrod, J. Electrochem. Soc., 152, A1165 (2005).

40. A. Damjanovic, M. Genshaw, and J. O. M. Bockris, J. Chem. Phys., 45, 4057 (1966).

41. H. Wroblowa, Y. Pan, and G. Razumney, J. Electroanal. Chem. Interfacial Electrochem., 69, 195 (1976).

42. A. Appleby, Catal. Rev, 4, 221 (1970).

43. K. Kinoshita, Electrochemical Oxygen Technology (Electrochemical Society Series), John Wiley \& Sons, New York (1992).

44. R. Adzic, in Electrocatalysis, J. Lipkowski and P. Ross, Editors, Chap. 5, WileyVCH, New York (1998).

45. Z. Shi, J. Zhang, Z.-S. Liu, H. Wang, and D. Wilkinson, Electrochim. Acta, 51, 1905 (2006).

46. A. Anderson and T. Albu, J. Electrochem. Soc., 147, A4229 (2000).

47. R. Sidik and A. Anderson, J. Electroanal. Chem., 528, 69 (2002).

48. A. Damjanovic and V. Brusic, Electrochim. Acta, 12, 615 (1967).

49. A. Panchenko, M. Koper, T. Shubina, S. Mitchell, and E. Roduner, J. Electrochem. Soc., 151, A2016 (2005).

50. N. M. Markovic, T. J. Schmidt, B. N. Grgur, H. A Gasteiger, R. J. Behm, and P. N. Ross, J. Phys. Chem. B, 103, 8568 (1999).

51. O. Antoine and R. Durand, J. Appl. Electrochem., 30, 839 (2000).

52. S. Chen and A. Kucernak, J. Phys. Chem. B, 108, 13984 (2004).

53. J. Wang, T. Springer, and R. Adzic, J. Electrochem. Soc., 153, A1732 (2006).

54. N. Markovic, B. Grour, and P. Ross, J. Phys. Chem. B, 101, 5405 (1997).

55. T. Zhang and A. Anderson, J. Phys. Chem. C, 111, 8644 (2007).

56. A. Anderson and Y. Cai, J. Phys. Chem. B, 108, 19917 (2004).

57. H. Wang and G. Capuano, J. Electrochem. Soc., 145, 780 (1998).

58. T. Lundström, H. Christensen, and K. Sehested, Radiat. Phys. Chem., 61, 109 (2001).

59. T. Lundström, H. Christensen, and K. Sehested, Radiat. Phys. Chem., 64, 29 (2002).

60. T. Schmidt, U. Paulus, H. Gasteiger, and R. Behm, J. Electroanal. Chem., 508, 41 (2001).

61. A. Michaelides and $\mathrm{P} . \mathrm{Hu}, J$. Chem Phys, 114, 513 (2001).

62. U. A. Paulus, A. Wokaun, G. G. Scherer, T. J. Schmidt, V. Stamenkovic, N. M. 
Markovic, and P. N. Ross, Electrochim. Acta, 47, 3787 (2002).

63. A. Anderson, Electrochim. Acta, 47, 3759 (2002).

64. A. LaConti, A. Fragala, and J. Boyack, in Proceedings of the Symposium on Electrode Materials and Process for Energy Conversion and Storage, J. McIntyre, S. Srinvasan, and F. Will, Editors, Vol. 77, pp. 354-374, The Electrochemical Society, Princeton, NJ (1977).

65. J. Wind, R. Spah, W. Kaiser, and G. Bohm, J. Power Sources, 105, 256 (2002).

66. R. Makkus, A. Janssen, F. de Bruijn, and R. M. Mallant, J. Power Sources, 86, 274 (2000).

67. J. Yu, T. Matsuura, Y. Yoshikawa, M. Islam, and M. Hori, Electrochem. Solid-State Lett., 8, A156 (2005).

68. F. Haber and J. Weiss, Proc. R. Soc. London, Ser. A 134, 332 (1934).

69. W. Barb, J. Baxendale, P. George, and K. Hargrave, Trans. Faraday Soc., 47, 462 (1951).

70. C. Zhou, M. Guerra, Z. Qiu, T. Zawodzinski, and D. Schiraldi, Macromolecules, 40, 8695 (2007).

71. V. Mittal, H. Kunz, and J. Fenton, J. Electrochem. Soc., 154, B652 (2007).

72. M. Kadirov, A. Bosnjakovic, and S. Schlick, J. Phys. Chem. B, 109, 7664 (2005).

73. A. Bosnjakovic and S. Schlick, J. Phys. Chem. B, 108, 4332 (2004)

74. A. A. Shah, G. S. Kim, W. Gervais, A. Young, K. Promislow, J. Li, and S. Ye, J. Power Sources, 160, 1251 (2006).

75. A. Shah, G. Kim, P. Sui, and D. Harvey, J. Power Sources, 163, 793 (2007).

76. A. Shah, P. Sui, G. Kim, and S. Ye, J. Power Sources, 166, 1 (2007).

77. A. Shah and F. Walsh, J. Power Sources, 185, 287 (2008).

78. Y. Wang and C.-Y. Wang, Electrochim. Acta, 50, 1307 (2005).

79. M. Fowler, R. Mann, J. Amphlett, B. Peppley, and P. Roberge, J. Power Sources, 106, 274 (2002)

80. L. Zhang and S. Mukerjee, J. Electrochem. Soc., 153, A1062 (2006)

81. B. Bird, W. Stewart, and E. Lightfoot, Transport Phenomena, John Wiley \& Sons, New York (2002)

82. A. Bertram, A. Ivanov, M. Hunter, L. Molina, and M. Molina, J. Phys. Chem. A, 105, 9415 (2001).

83. C. Wilke and P. Chang, AIChE J., 1, 264 (1955).

84. R. Reid, J. Praunsnitz, and T. Sherwood, The Properties of Gases and Liquids, 3rd ed., McGraw-Hill, New York (1977).

85. G. Le Bas, The Molecular Volumes of Liquid Chemical Compounds, Longman, Green, New York (1915).

86. M. Tyn and W. Calus, Processing, 21, 16 (1975).

87. C. Satterfield, Mass Transfer in Heterogeneous Catalysis, MIT Press, Cambridge, MA (1970).

88. S. Motupally, A. Becker, and J. Weidner, J. Electrochem. Soc., 147, A3171 (2000).

89. T. Springer, T. Zawodzinski, and S. Gottesfeld, J. Electrochem. Soc., 138, A2334 (1991).

90. J. Hinatsu, M. Mizuhata, and H. Takenaka, J. Electrochem. Soc., 141, A1493 (1994).

91. S. Ge, X. Li, B. Yi, and I. Hsing, J. Electrochem. Soc., 152, A1149 (2005).

92. V. Mittal, H. Kunz, and J. Fenton, Electrochem. Solid-State Lett., 9, A299 (2006).

93. A. Ohma, S. Suga, S. Yamamoto, and K. Shinohara, J. Electrochem. Soc., 154,
B757 (2007)

94. K. Mauritz and R. Moore, Chem Rev (Washington, D. C.), 104, 4535 (2004).

95. J. J. Baschuk and X. Li, Int. J. Energy Res., 27, 1095 (2003).

96. T. Lundström, H. Christensen, and K. Sehested, Radiat. Phys. Chem., 69, 211 (2004).

97. G. Scherer, Ber. Bunsenges. Phys. Chem., 94, 1008 (1990).

98. V. Mittal, H. Kunz, and J. Fenton, J. Electrochem. Soc., 153, A1755 (2006).

99. M. Inaba, M. Kiriake, A. Tasaka, T. Kinumoto, and Z. Ogumi, in Extended Abstracts of the 11th Fuel Cell Symposium, Fuel Cell Development Information Center, Tokyo, p. 261 (2003).

100. V. Sethuraman, J. Weidner, A. Haung, and L. Protsailo, J. Electrochem. Soc., 155 B119 (2008).

101. H. Yu, C. Ziegler, M. Oszcipoka, M. Zobela, and C. Hebling, J. Power Sources, 51, 1199 (2006)

102. T. Schultz and K. Sundmacher, J. Power Sources, 145, 435 (2005).

103. M. Mathias, J. Roth, J. Fleming, and W. Lehnert, in Handbook of Fuel CellsFundamentals, Technology and Applications, Vol. 3, W. Vielstich, A. Lamm, and H. Gasteiger, Editors, Chap. 46, John Wiley \& Sons, New York (2003).

104. S. Lister and G. McLean, J. Power Sources, 130, 61 (2004).

105. T. V. Nguyen and W. He, in Handbook of Fuel Cells-Fundamentals, Technology and Applications, Vol. 3, W. Vielstich, A. Lamm, and H. Gasteiger, Editors, Chap 46, John Wiley \& Sons, New York (2003).

106. U. Pasaogullari, C.-Y. Wang, and K. Chen, J. Electrochem. Soc., 152, A1574 (2005).

107. C. Ziegler, H. Yu, and J. Schumacher, J. Electrochem. Soc., 152, A1555 (2005).

108. K. Bhatia and C.-Y. Wang, Electrochim. Acta, 49, 2333 (2004).

109. M. Williams, E. Begg, L. Bonville, H. Kunz, and J. Fenton, J. Electrochem. Soc., 151, A1173 (2004).

110. J. Hwang, Trans. ASME, J. Appl. Mech., 128, 434 (2006).

111. R. Weast, CRC Handbook of Chemistry and Physics, 67th ed., CRC Press, Boca Raton, FL (1986).

112. S. Um, C.-Y. Wang, and K. S. Chen, J. Electrochem. Soc., 147, A4485 (2000).

113. N. Siegel, M. Ellis, D. Nelson, and M. von Spakovsky, J. Power Sources, 115, 81 (2003).

114. D. O'Sullivan, M. Lee, B. Noone, and B. Heikes, J. Phys. Chem., 100, 3241 (1996).

115. P. Brimblecombe and S. L. Clegg, J. Atmos. Chem., 7, 1 (1988); P. Brimblecombe and S. L. Clegg, J. Atmos. Chem., 8, 95 (1989).

116. D. Hanson, J. Burkholder, C. Howard, and A. Ravishankara, J. Phys. Chem., 96, 49794985 (1992).

117. W. He, J. Yi, and T. Nguyen, AIChE J., 46, 2053 (2000).

118. M. Khandelwal and M. Mench, J. Power Sources, 161, 1106 (2006).

119. W. Wagner and A. Pruss, J. Phys. Chem. Ref. Data, 31, 387 (2002).

120. R. Powell and R. Tye, Br. J. Appl. Phys., 14, 662 (1963).

121. Fuel Cell Scientific, http://fuelcellsupplies.net/torayspecsheet.html, last accessed Oct 1, 2008.

122. NIST Webbook, http://www.webbook.nist.gov, last accessed Oct 1, 2008

123. M. Lampinen and M. Fomino, J. Electrochem. Soc., 140, A3537 (1993) 